\title{
Manganese/Copper Co-Catalyzed Electrochemical Wacker-Tsuji-Type Oxidation of Aryl-Substituted Alkenes
}

\author{
Junshan Lai, ${ }^{\mathrm{a}, \mathrm{b}}$ and Miquel A. Pericàs $\mathrm{s}^{\mathrm{a}, \mathrm{c}, *}$ \\ a Institute of Chemical Research of Catalonia (ICIQ), The Barcelona Institute of Science and \\ Technology, Av. Països Catalans, 16, 43007 Tarragona,Spain \\ b Departament de Química Analítica i Química Orgànica, Universitat Rovira i Virgili, 43007 Tarragona, \\ Spain \\ ${ }^{c}$ Departament de Química Inorgànica i Orgànica, Universitat de Barcelona, Martí i Franquès 1- \\ 11,08028 Barcelona, Spain \\ mapericas@iciq.es
}

\section{Table of Contents}

1. General information $\quad$ S2

2. General procedure for the electrochemical Wacker-Tsuji-type oxidation S2

3. Initial screening of solvents and catalysts $\quad$ S3

4. Optimization of the different reaction parameters $\quad$ S5

5. Cyclic voltammetry studies $\quad$ S9

6. Mechanistic studies: detection of bromohydrin III and conversion into acetophenone 2a under electrochemical conditions $\quad \mathrm{S10}$

7. Compound characterization data $\mathrm{S11}$

8. References $\quad \mathrm{S} 16$

$\begin{array}{lr}\text { 9. NMR Spectra } & \text { S17 }\end{array}$ 


\section{General information}

Unless otherwise noted, all reactions were conducted under air. All commercial reagents and solvents were used as received. Starting compounds $\mathbf{1 a - z}$ are all known. 1a-x, and $\mathbf{1 z}$ were commercially available and were used as received, while $1 \mathrm{y}$ was prepared by a reported procedure ${ }^{1}$. Flash chromatography was carried out using 60 mesh silica gel and dry-packed columns. Thin layer chromatography was carried out using Merck TLC Silicagel 60 F254 aluminum sheets. Components were visualized by UV light $(\lambda=254 \mathrm{~nm})$ and stained with phosphomolybdic dip. NMR spectra were recorded at $298 \mathrm{~K}$ on a Bruker Avance 400 Ultrashield apparatus. ${ }^{1} \mathrm{H}$ NMR spectroscopy chemical shifts are quoted in ppm relative to tetramethylsilane (TMS). $\mathrm{CDCl}_{3}$ was used as internal standard for ${ }^{13} \mathrm{C}$ NMR spectra. Chemical shifts are given in ppm and coupling constants in $\mathrm{Hz}$.

\section{General procedure for the electrochemical Wacker-Tsuji-type oxidation}
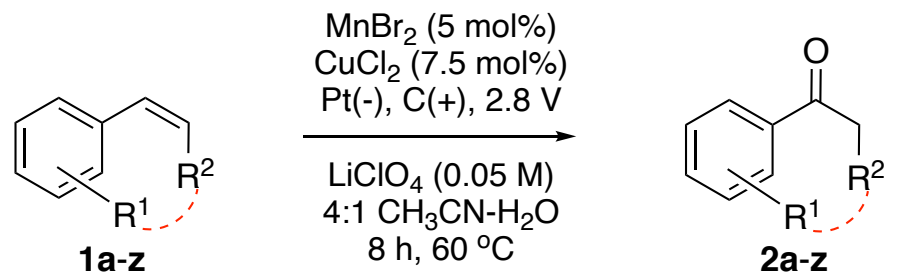

Experiments were performed using a DC power supply. The reaction vessel was a simple glass tube equipped with a rubber septum and carbon felt (G200, $10 \mathrm{~mm} \times 10 \mathrm{~mm} \times 5 \mathrm{~mm}$ ) as the anode and platinum plate $(10 \mathrm{~mm} \times 10 \mathrm{~mm} \times 0.25 \mathrm{~mm})$ as the cathode. Experiments were normally performed under air atmosphere. For experiments under exclusion of oxygen, the cell was sealed and flushed with argon for 15 minutes. To the undivided glass tube $(10 \mathrm{~mL})$ used as electrochemical cell, $\mathrm{MnBr}_{2}(10.7$ $\mathrm{mg}, 0.05 \mathrm{mmol}, 5 \mathrm{~mol} \%), \mathrm{CuCl}_{2}\left(10.1 \mathrm{mg}, 0.075 \mathrm{mmol}, 7.5 \mathrm{~mol} \%\right.$ ) and $\mathrm{LiClO}_{4}$ solution $(3 \mathrm{~mL}, 0.05 \mathrm{M}$ in a 4:1 vol/vol MeCN/water) were added, followed by the addition of the reacting olefins $(1 \mathrm{mmol})$ via syringe. The cell was placed in an oil bath heated at $60^{\circ} \mathrm{C}$, and current pass was then started at a constant potential of $2.8 \mathrm{~V}$ and kept under these conditions for $8 \mathrm{~h}$, when TLC analysis indicated that the reaction was complete. The solution was then transferred to a round-bottom flask, and the reaction flask and the electrodes were washed with DCM which was combined with the reaction mixture. The solvents were directly evaporated under reduced pressure, and the residue was submitted to purification by flash column chromatography on silicagel, eluting with solvent mixtures specified in Section 7 for each particular case. 


\section{Initial screening of solvents and catalysts}

\subsection{Table S1. Screening of reaction conditions: solvent and catalyst ${ }^{a}$}

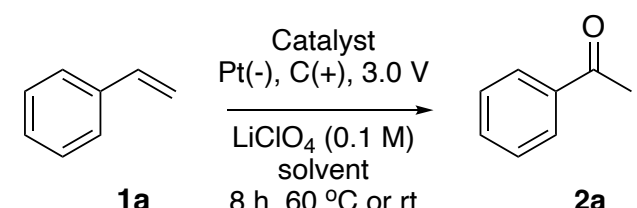

\begin{tabular}{|c|c|c|c|}
\hline entry & Solvent/ $\mathrm{H}_{2} \mathrm{O}(\mathrm{v}: \mathrm{v})^{\mathrm{b}}$ & Catalyst $^{\mathrm{c}}$ & yield [\%] \\
\hline S1 & $\mathrm{MeOH}(1: 1)$ & $\mathrm{MnBr}_{2}$ & trace \\
\hline S2 & EtOH (1:1) & $\mathrm{MnBr}_{2}$ & trace \\
\hline S3 & 'PrOH (1:1) & $\mathrm{MnBr}_{2}$ & 10 \\
\hline S4 & DMF (1:1) & $\mathrm{MnBr}_{2}$ & trace \\
\hline S5 & Acetone (1:1) & $\mathrm{MnBr}_{2}$ & 12 \\
\hline S6 & $\operatorname{MeCN}(1: 1)$ & $\mathrm{MnBr}_{2}$ & 23 \\
\hline S7 & $\operatorname{MeCN}(4: 1)$ & $\mathrm{MnBr}_{2}$ & 28 \\
\hline$S 8^{e}$ & $\operatorname{MeCN}(4: 1)$ & $\mathrm{MnBr}_{2}$ & 15 \\
\hline S9 & $\operatorname{MeCN}(4: 1)$ & $\mathrm{NiCl}_{2}$ & $n d^{e}$ \\
\hline S10 & $\operatorname{MeCN}(4: 1)$ & $\mathrm{FeCl}_{3}$ & $n d^{e}$ \\
\hline S11 & $\operatorname{MeCN}(4: 1)$ & $\mathrm{PdCl}_{2}$ & trace \\
\hline S12 & $\operatorname{MeCN}(4: 1)$ & $\mathrm{MnBr}_{2}, \mathrm{CuCl}_{2}$ & 67 \\
\hline S13 & $\operatorname{MeCN}(4: 1)$ & $\mathrm{CuCl}_{2}$ & $n d^{f}$ \\
\hline
\end{tabular}

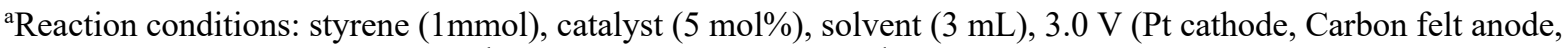
$\left.0.1 \mathrm{M} \mathrm{LiClO}_{4}\right), 60{ }^{\circ} \mathrm{C}$, Argon, $8 \mathrm{~h}$. ${ }^{\mathrm{b}}$ Solvent:water ratio. ${ }^{\mathrm{c}} 5 \mathrm{~mol}{ }^{\mathrm{d}}$ Isolated yield. $\%$. ${ }^{\circ}$ Reaction at room temperature. fot detected. 


\subsection{Table S2. Optimization of reaction conditions: copper and manganese}

sources $^{a}$

\begin{tabular}{|c|c|c|c|}
\hline & $\begin{array}{l}\mathrm{C} \\
\mathrm{P} \\
\mathrm{L}\end{array}$ & $\begin{array}{c}\mathrm{Mn}(5 \mathrm{~mol} \%) \\
\mathrm{Cu}(7.5 \mathrm{~mol} \%) \\
\mathrm{Ot(-)}, \mathrm{C}(+), 2.8 \mathrm{~V} \\
\underset{\mathrm{LiClO}_{4}(0.05 \mathrm{M})}{\longrightarrow} \\
4: 1 \mathrm{CH}_{3} \mathrm{CN}-\mathrm{H}_{2} \mathrm{O} \\
8 \mathrm{~h}, 60^{\circ} \mathrm{C}\end{array}$ & $2 a$ \\
\hline entry & Cu source & $\mathrm{Mn}$ or $\mathrm{Br}$ source & yield [\%] \\
\hline S1 & $\mathrm{CuBr}_{2}$ & $\mathrm{MnBr}_{2}$ & 86 \\
\hline S2 & $\mathrm{Cu}(\mathrm{OAc})_{2}$ & $\mathrm{MnBr}_{2}$ & 35 \\
\hline S3 & Cul & $\mathrm{MnBr}_{2}$ & 10 \\
\hline S4 & $\mathrm{Cu}(\mathrm{OTf})_{2}$ & $\mathrm{MnBr}_{2}$ & 44 \\
\hline S5 & $\mathrm{CuCl}_{2}$ & $\mathrm{MnBr}_{2}$ & 85 \\
\hline S6 & $\mathrm{Cu}(\mathrm{acac})_{2}$ & $\mathrm{MnBr}_{2}$ & trace \\
\hline S7 & $\mathrm{CuCN}$ & $\mathrm{MnBr}_{2}$ & 10 \\
\hline S8 & $\mathrm{CuSO}_{4}$ & $\mathrm{MnBr}_{2}$ & 27 \\
\hline S9 & $\mathrm{Cu}(\mathrm{TFA})_{2}$ & $\mathrm{MnBr}_{2}$ & 49 \\
\hline $\mathrm{S} 10$ & Cu beads & $\mathrm{MnBr}_{2}$ & 53 \\
\hline $\mathrm{S} 11$ & Cu beads & $\mathrm{MnO}_{2}$ & trace \\
\hline $\mathrm{S} 12$ & $\mathrm{CuCl}_{2}$ & $\mathrm{MnCl}_{2}$ & 40 \\
\hline $\mathrm{S} 13$ & $\mathrm{Cu}(\mathrm{OAc})_{2}$ & $\mathrm{Mn}(\mathrm{OAC})_{2}$ & trace \\
\hline $\mathrm{S} 14$ & $\mathrm{CuSO}_{4}$ & $\mathrm{MnSO}_{4}$ & trace \\
\hline $\mathrm{S} 15$ & $\mathrm{CuBr}_{2}$ & $\mathrm{MnCl}_{2}$ & 80 \\
\hline $\mathrm{S} 16$ & $\mathrm{CuBr}_{2}$ & - & trace \\
\hline S17 & $\mathrm{CuCl}_{2}$ & $\mathrm{NaBr}$ & trace \\
\hline $\mathrm{S} 18$ & $\mathrm{CuCl}_{2}$ & $\mathrm{HBr}$ & trace \\
\hline $\mathrm{S} 19$ & $\mathrm{CuCl}_{2}$ & ${ }^{n} \mathrm{Bu}_{4} \mathrm{~N}^{+} \mathrm{Br}^{-}$ & trace \\
\hline $\mathrm{S} 20$ & $\mathrm{CuCl}_{2}$ & - & trace \\
\hline
\end{tabular}

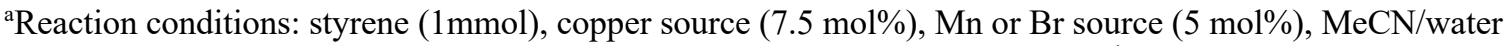
(5:1) $(3 \mathrm{~mL}), 2.8 \mathrm{~V}$ (Pt cathode, Carbon felt anode, $\left.0.05 \mathrm{M} \mathrm{LiClO}_{4}\right), 60{ }^{\circ} \mathrm{C}, 8 \mathrm{~h} .{ }^{\mathrm{b}}$ Isolated yield. 


\section{Optimization of the different reaction parameters}

\subsection{Amount of $\mathrm{MnBr}_{2}$}

Different experiments were performed according to the general procedure varying the amount of $\mathrm{MnBr}_{2}$ between 0 and $10 \mathrm{~mol} \%$. Results are summarized in Figure S1.
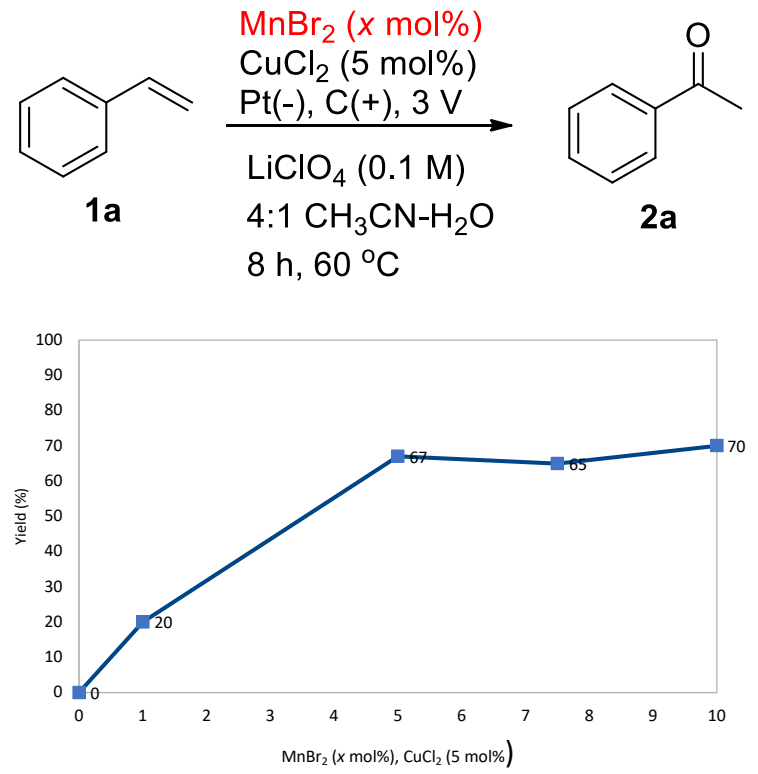

Figure S1. Reaction conditions: $\mathrm{MnBr}_{2}$ (x mol\%), $\mathrm{CuCl}_{2}(6.8 \mathrm{mg}, 0.05 \mathrm{mmol}, 5 \mathrm{~mol} \%$ ), styrene (104 mg, $1 \mathrm{mmol})$, $\mathrm{LiClO}_{4}$ solution [0.1 M in 4:1 MeCN/water (3 mL)], $\mathrm{Pt}(-), \mathrm{C}(+), 3.0 \mathrm{~V}, 8 \mathrm{~h}, 60{ }^{\circ} \mathrm{C}$.

\subsection{Amount of $\mathrm{CuCl}_{2}$}

Different experiments were performed according to the general procedure varying the amount of $\mathrm{CuCl}_{2}$ between 0 and $15 \mathrm{~mol} \%$. Results are summarized in Figure S2.
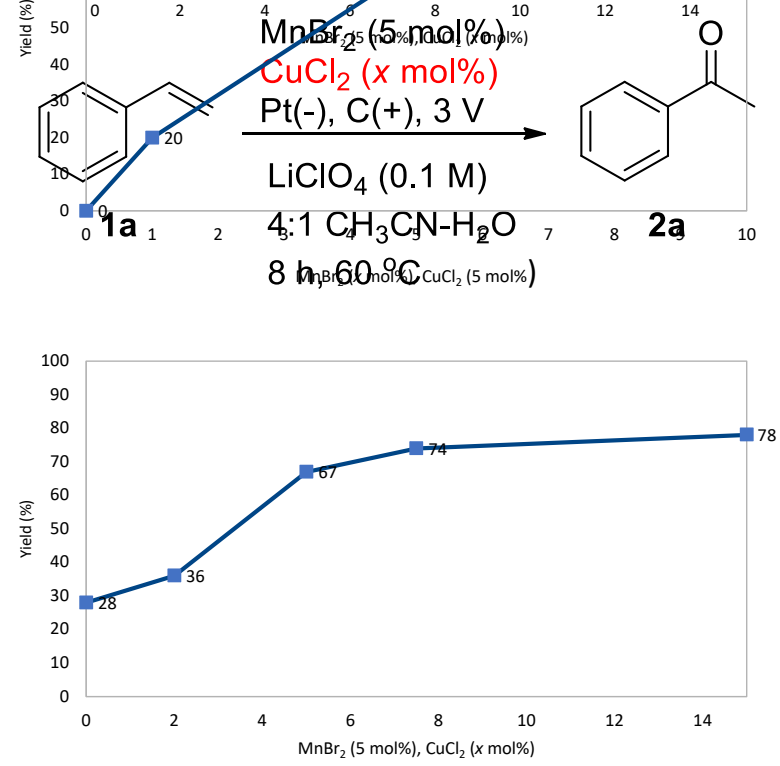

Figure S2. Reaction conditions: $\mathrm{MnBr}_{2}(10.7 \mathrm{mg}, 0.05 \mathrm{mmol}, 5 \mathrm{~mol} \%), \mathrm{CuCl}_{2}$ (x mol\%), styrene (104 $\mathrm{mg}, 1 \mathrm{mmol})$, $\mathrm{LiClO}_{4}$ solution [0.1 M in 4:1 MeCN/water $(3 \mathrm{~mL})$ ], $\mathrm{Pt}(-), \mathrm{C}(+), 3.0 \mathrm{~V}, 8 \mathrm{~h}, 60{ }^{\circ} \mathrm{C}$. 


\subsection{Amount of water in acetonitrile/water solvent mixtures}

Different experiments were performed according to the general procedure in acetonitrile/water solvent mixtures with compositions ranging from $100 \%$ acetonitrile to $100 \%$ water. Results are summarized in Figure S3.
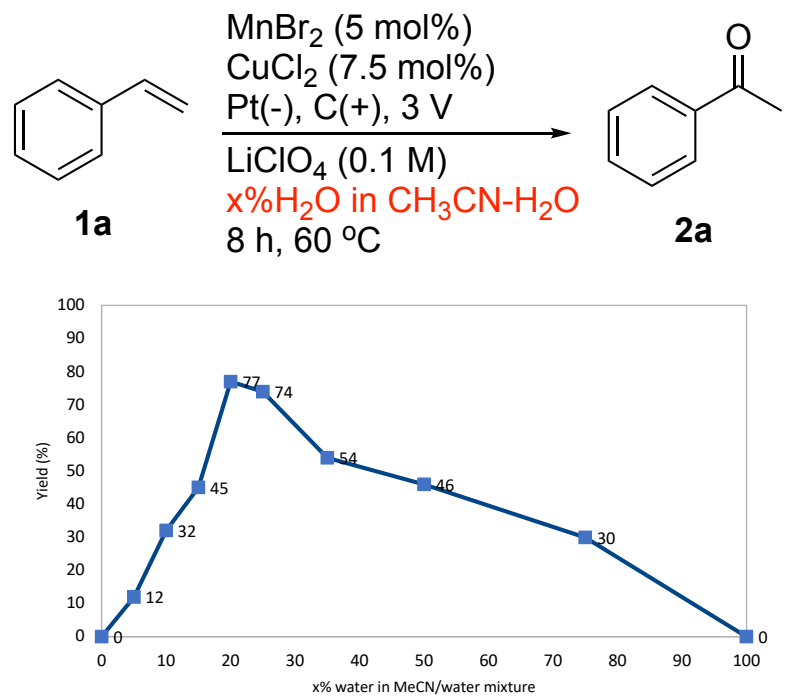

Figure S3. Reaction conditions: $\mathrm{MnBr}_{2}(10.7 \mathrm{mg}, 0.05 \mathrm{mmol}, 5 \mathrm{~mol} \%), \mathrm{CuCl}_{2}(10.1 \mathrm{mg}, 0.075 \mathrm{mmol}$, $7.5 \mathrm{~mol} \%$ ), styrene (104 mg, $1 \mathrm{mmol}$ ), $\mathrm{LiClO}_{4}$ solution $(0.1 \mathrm{M}$ in $3 \mathrm{~mL}$ of $\mathrm{MeCN} /$ water with the indicated $\mathrm{vol} / \mathrm{vol}$ compositions), $\mathrm{Pt}(-), \mathrm{C}(+), 3.0 \mathrm{~V}, 8 \mathrm{~h}, 60^{\circ} \mathrm{C}$.

\subsection{Amount of Styrene}

Different experiments were performed according to the general procedure varying the amount of styrene between $0.25 \mathrm{mmol}$ and $3.00 \mathrm{mmol}$. Results are summarized in Figure S4.
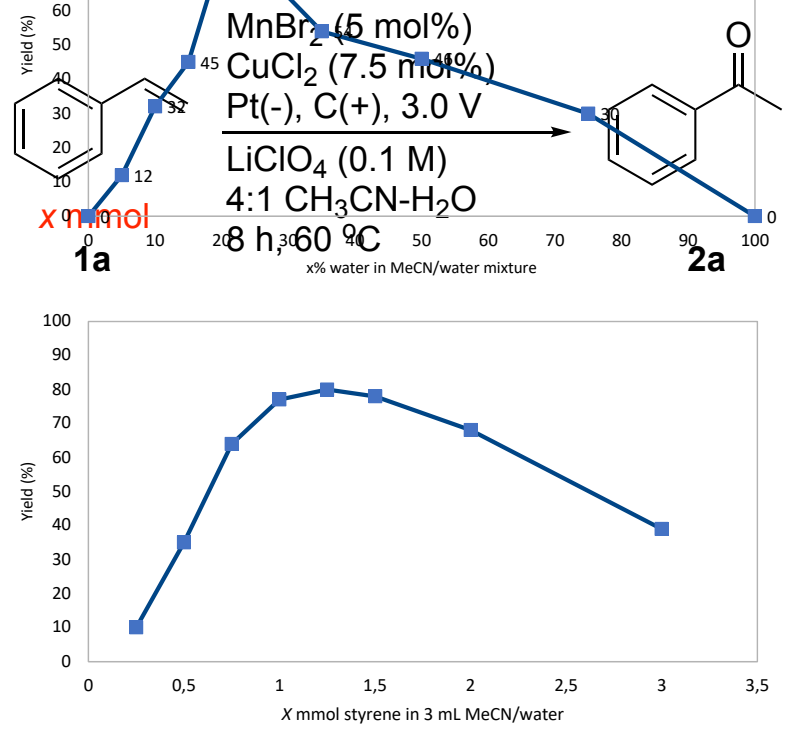

Figure S4. Reaction conditions: $\mathrm{MnBr}_{2}(10.7 \mathrm{mg}, 0.05 \mathrm{mmol}, 5 \mathrm{~mol} \%), \mathrm{CuCl}_{2}(10.1 \mathrm{mg}, 0.075 \mathrm{mmol}$, $7.5 \mathrm{~mol} \%)$, styrene (x mmol), $\mathrm{LiClO}_{4}$ solution [0.1 M in 4:1 MeCN/water $\left.(3 \mathrm{~mL})\right], \mathrm{Pt}(-), \mathrm{C}(+), 3.0 \mathrm{~V}, 8 \mathrm{~h}$, $60^{\circ} \mathrm{C}$. 


\subsection{Concentration of $\mathrm{LiClO}_{4}$ solution}

Different experiments were performed according to the general procedure varying the concentration of $\mathrm{LiClO}_{4}$ in 4:1 MeCN/water between 0.025 and $0.30 \mathrm{M}$. Results are summarized in Figure S5.
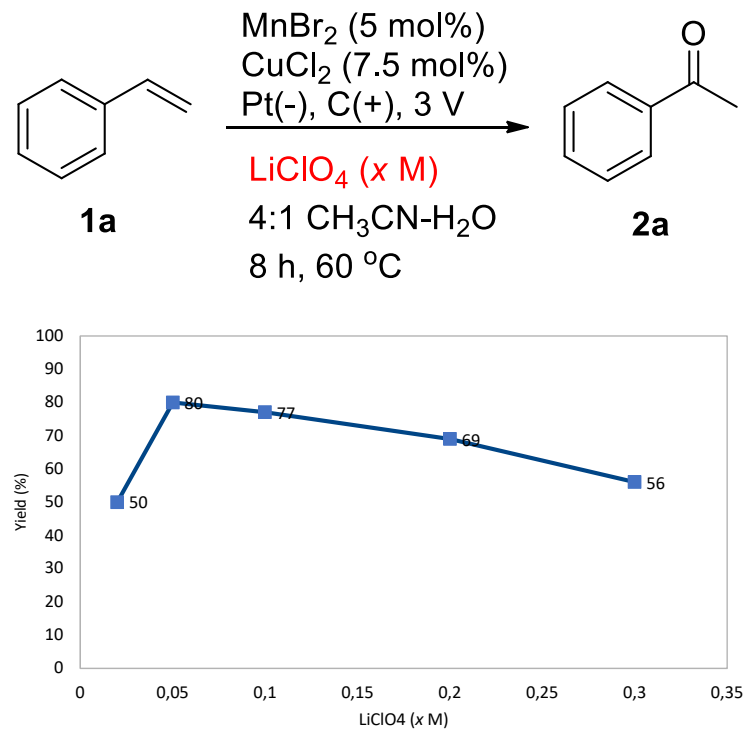

Figure S5. Reaction conditions: $\mathrm{MnBr}_{2}(10.7 \mathrm{mg}, 0.05 \mathrm{mmol}, 5 \mathrm{~mol} \%), \mathrm{CuCl}_{2}(10.1 \mathrm{mg}, 0.075 \mathrm{mmol}$, $7.5 \mathrm{~mol} \%$ ), styrene (104 mg, $1 \mathrm{mmol}$ ), $\mathrm{LiClO}_{4}$ solution [ $x \mathrm{M}$ in 4:1 MeCN/water(3 mL)], Pt(-), C(+), 3.0 $\mathrm{V}, 8 \mathrm{~h}, 60^{\circ} \mathrm{C}$.

\subsection{Applied potential}

Different experiments were performed according to the general procedure varying the applied potential between 1.7 and 3.4 V. Results are summarized in Figure S6.
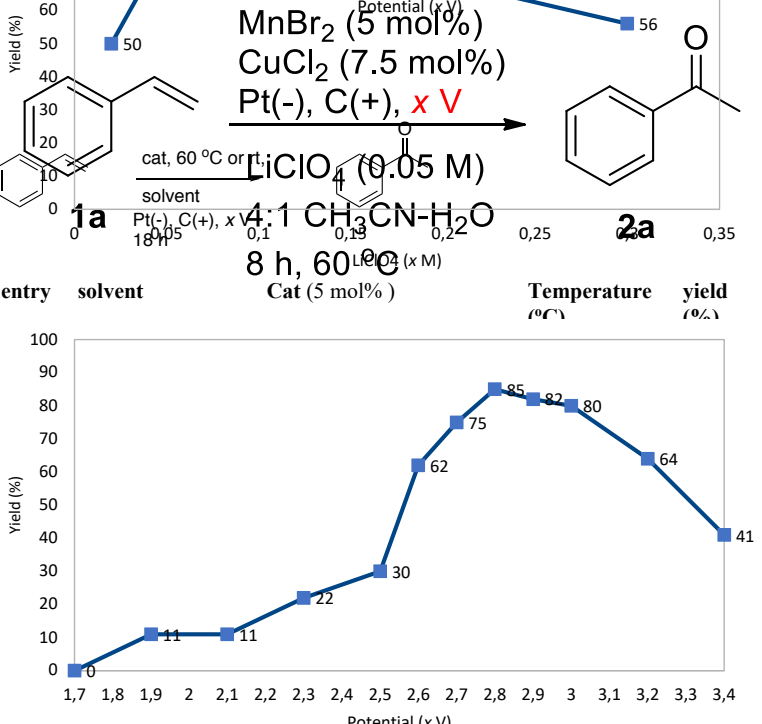

Figure S6. Reaction conditions: $\mathrm{MnBr}_{2}(10.7 \mathrm{mg}, 0.05 \mathrm{mmol}, 5 \mathrm{~mol} \%), \mathrm{CuCl}_{2}(10.1 \mathrm{mg}, 0.075 \mathrm{mmol}$, $7.5 \mathrm{~mol} \%$ ), styrene (104 mg, $1 \mathrm{mmol}$ ), $\mathrm{LiClO}_{4}$ solution [0.05 $\mathrm{M}$ in 4:1 $\left.\mathrm{MeCN} / w a t e r(3 \mathrm{~mL})\right], \mathrm{Pt}(-), \mathrm{C}(+), \mathrm{x}$ $\mathrm{V}, 8 \mathrm{~h}, 60^{\circ} \mathrm{C}$. 
The study was repeated in a single compartment, three electrode cell including an $\mathrm{Ag} / \mathrm{AgCl}$ reference electrode. The results are summarized in Figure S7 for potentials ranging from 2.4 to $3.0 \mathrm{~V}$. Each point corresponds to the mean value of two independent determinations.
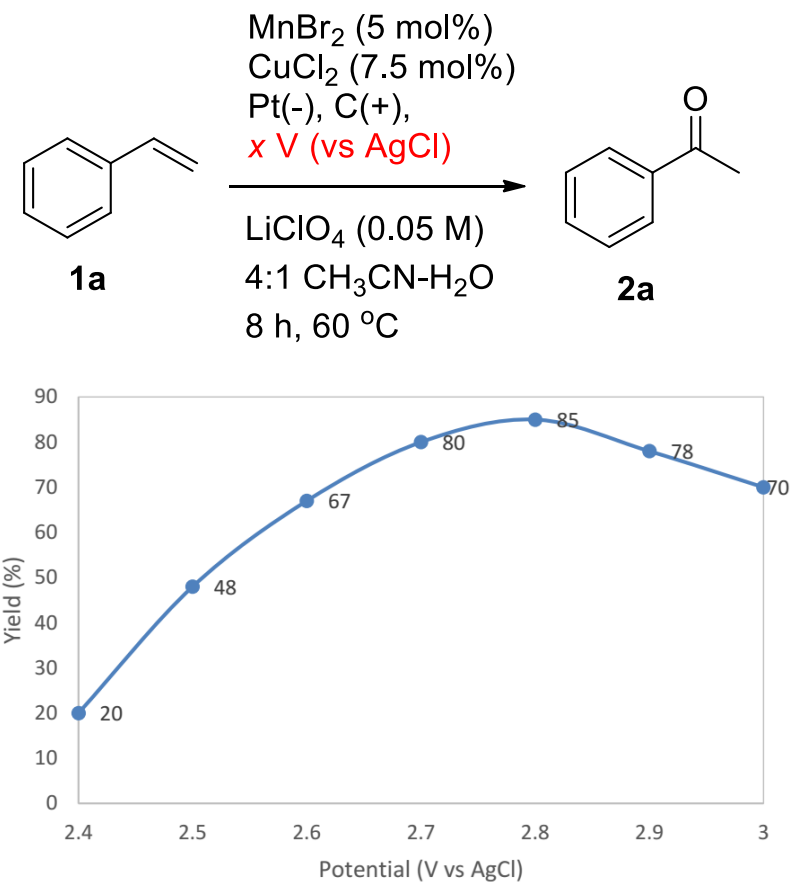

Figure S7. Reaction conditions: $\mathrm{MnBr}_{2}(10.7 \mathrm{mg}, 0.05 \mathrm{mmol}, 5 \mathrm{~mol} \%), \mathrm{CuCl}_{2}(10.1 \mathrm{mg}, 0.075 \mathrm{mmol}$, $7.5 \mathrm{~mol} \%$ ), styrene (104 mg, $1 \mathrm{mmol}$ ), $\mathrm{LiClO}_{4}$ solution [0.05 M in 4:1 MeCN/water(3 mL)], Pt(-), C(+), (x V vs $\mathrm{AgCl}), 8 \mathrm{~h}, 60^{\circ} \mathrm{C}$. 


\section{Cyclic voltammetry studies}

Cyclic voltammetry (CV) experiments were conducted in a $5 \mathrm{~mL}$ glass vial equipped with a glassy carbon working electrode, an $\mathrm{Ag} / \mathrm{AgCl}$ reference electrode, and a platinum wire counter electrode. $\mathrm{Ag} / \mathrm{AgCl}$ reference electrodes were stored in $0.1 \mathrm{M} \mathrm{LiClO}_{4}$ in acetonitrile. Concentrations of the individual individual components were $8 \mathrm{mM}$. The blank experiment refers to $0.1 \mathrm{M} \mathrm{LiClO}_{4}$ in $4: 1(\mathrm{v} / \mathrm{v})$ $\mathrm{CH}_{3} \mathrm{CN} / \mathrm{H}_{2} \mathrm{O}$. Scan rate was $50 \mathrm{mV} / \mathrm{s}$. In the case of 5 eq. styrene, the concentration of styrene is 40 $\mathrm{mM}$.

a)

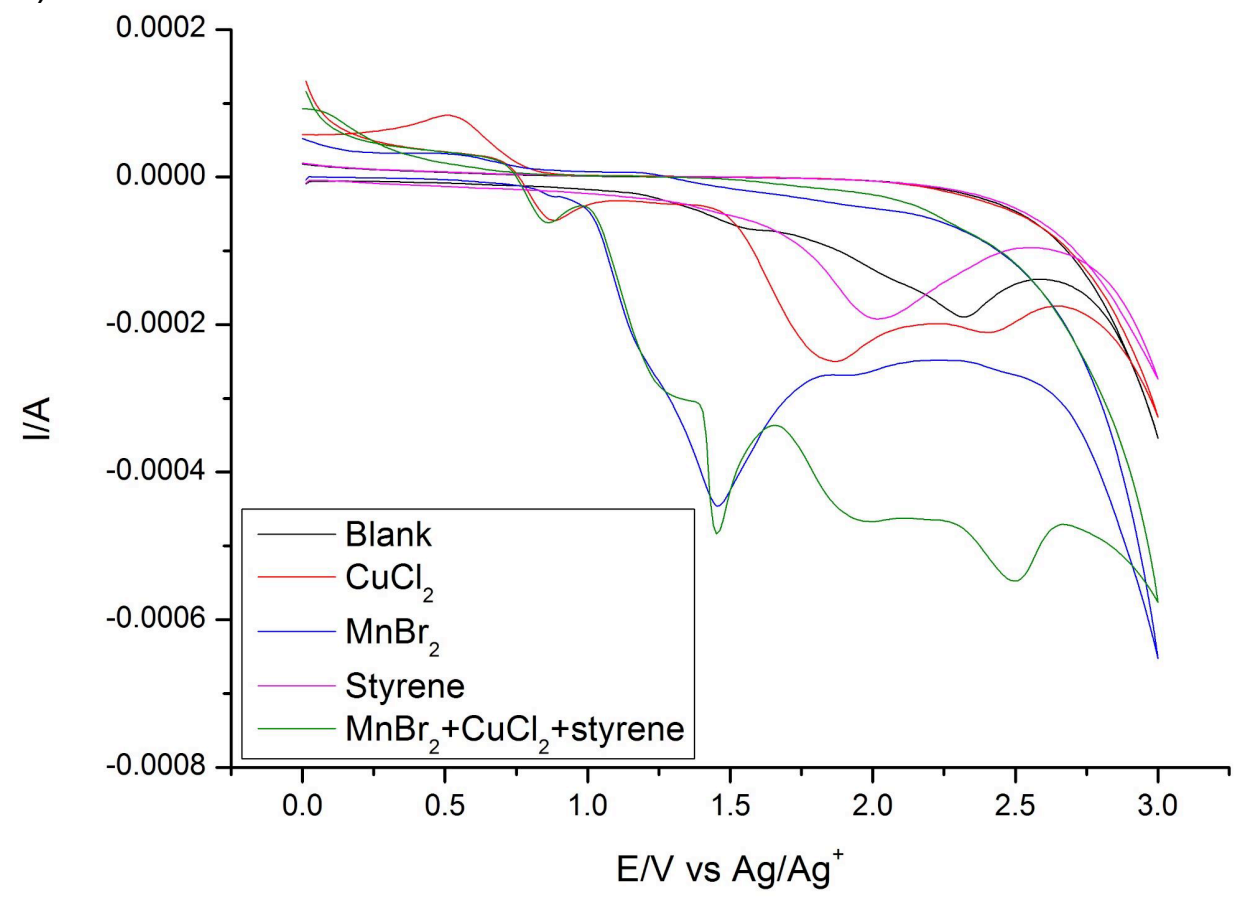

b)

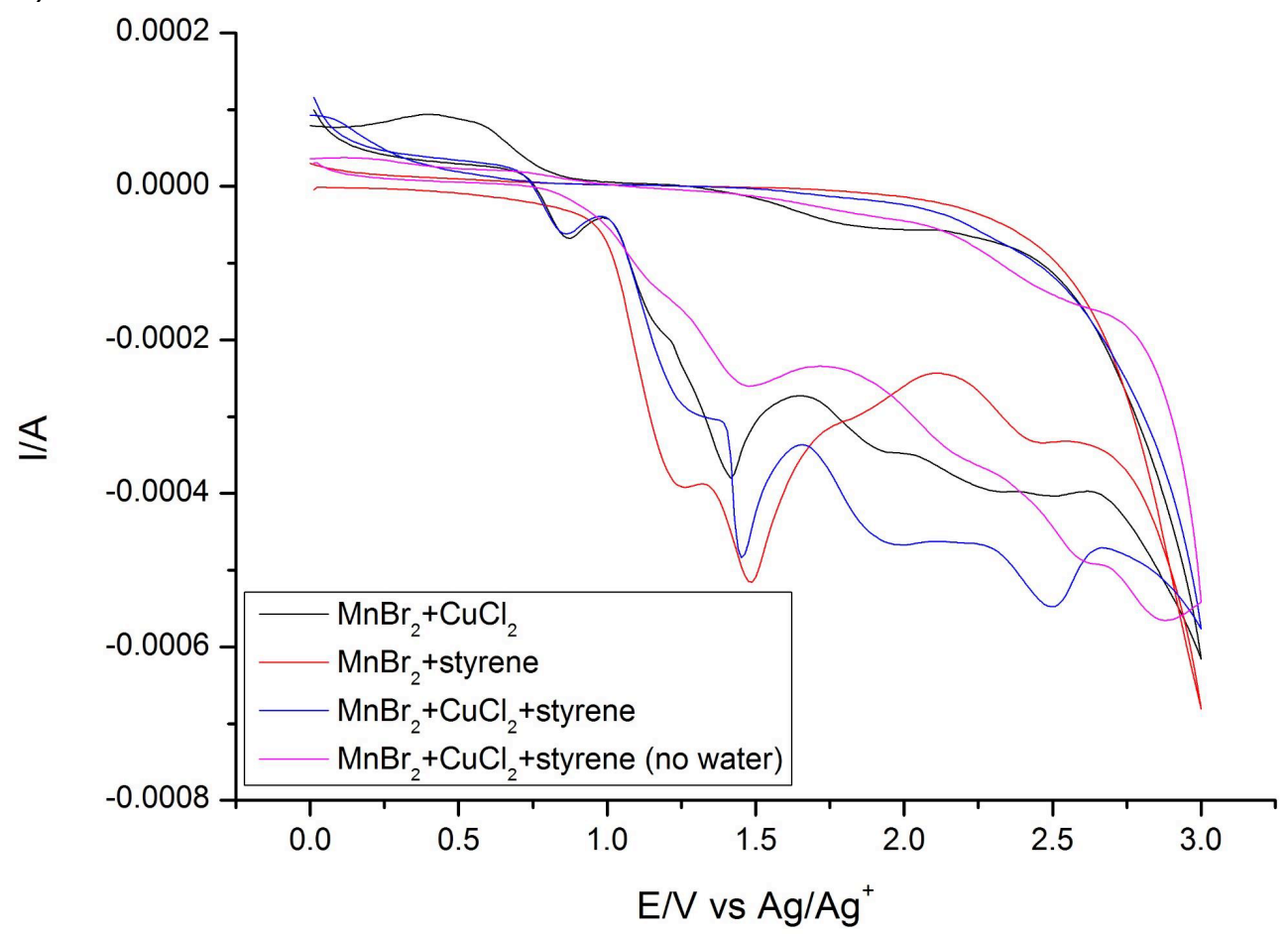


6. Mechanistic studies: detection of bromohydrin III and conversion into acetophenone 2a under electrochemical conditions.

a) ${ }^{1} \mathrm{H}$ NMR spectra of a reaction crude of the electrochemical oxidation of styrene leading to $2 \mathrm{a}$, showing the presence of bromohydrin III.

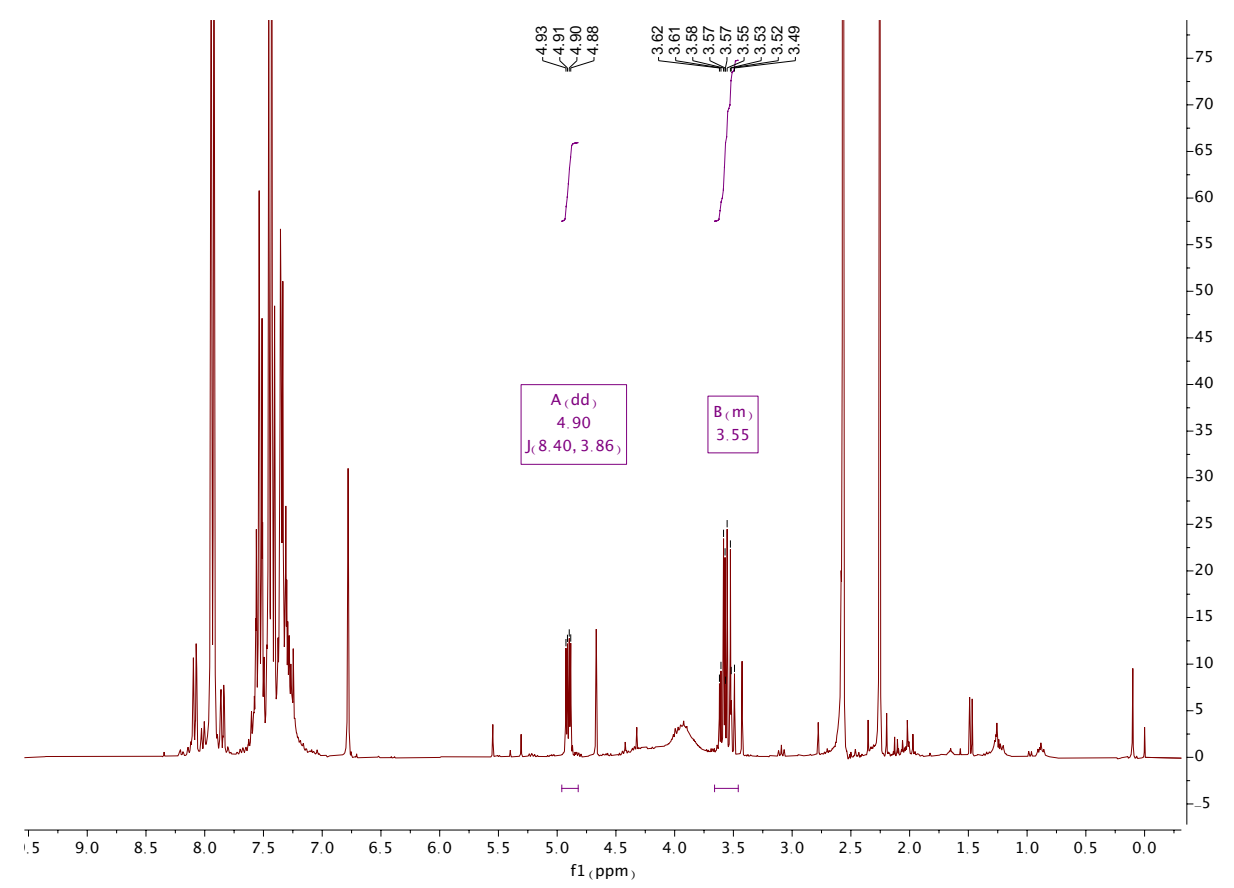

b) ${ }^{1} \mathrm{H}$ NMR spectra of an authentic sample of bromohydrin III

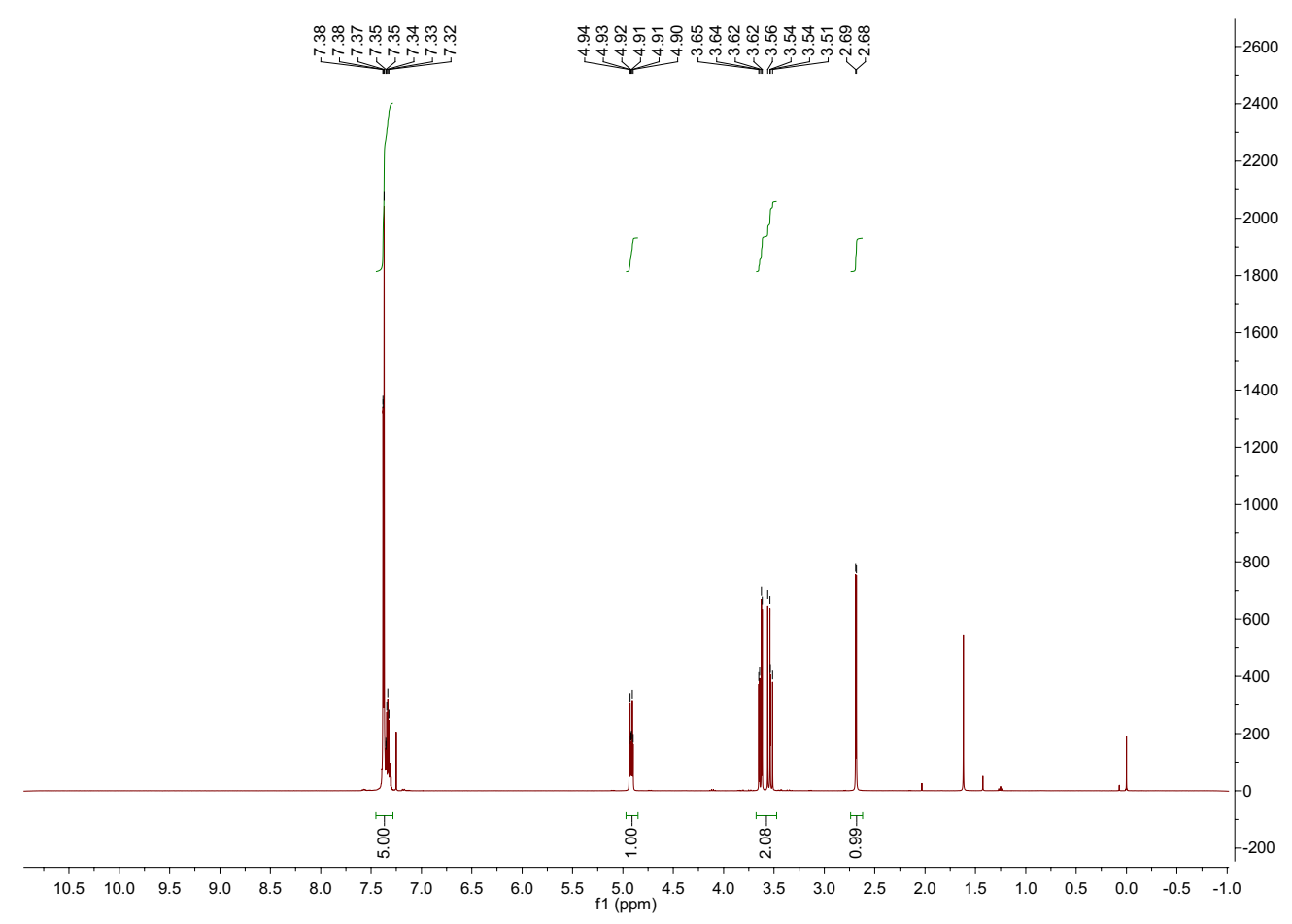


c) Conversion of bromohydrin III into acetophenone $\mathbf{2 a}$ under electrochemical conditions

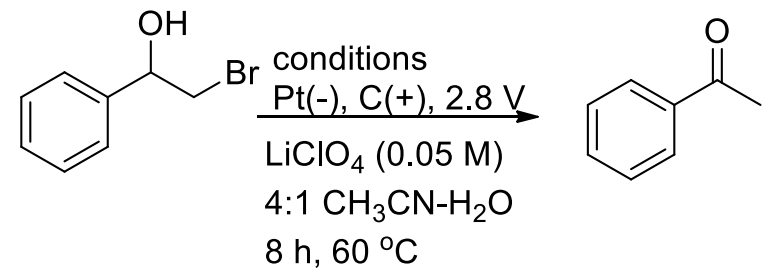

\begin{tabular}{|c|c|c|c|}
\hline Conditions & Conversion [\%] & Yield [\%] & $\begin{array}{c}\text { Selectivity [\%] } \\
\left.\text { (100.yield.conv }{ }^{-1}\right)\end{array}$ \\
\hline $\mathrm{CuCl}_{2}(7.5 \mathrm{~mol} \%)$ & 40 & 35 & 87.5 \\
\hline $\mathrm{MnBr}_{2}(5 \mathrm{~mol} \%)$ & 58 & 50 & 86.2 \\
\hline $\mathrm{CuCl}_{2}\left(7.5 \mathrm{~mol}^{2}\right), \mathrm{MnBr}_{2}(5 \mathrm{~mol} \%)$ & 55 & 50 & 90.9 \\
\hline no metal catalyst & 50 & 35 & 70.0 \\
\hline
\end{tabular}

\section{Compound characterization data}<smiles>CC(=O)c1ccccc1</smiles>

2a

Acetophenone (2a). The general procedure was followed from $1 \mathrm{a}(0.104 \mathrm{~g}, 1 \mathrm{mmol})$ to afford $2 \mathrm{a}(0.103$ $\mathrm{g}, 0.85 \mathrm{mmol}, 85 \%$ yield) as colorless oil. 2a was purified by column chromatography on silica gel, eluting with ethyl acetate cyclohexane mixtures $\left(E t O A c / \mathrm{C}_{6} \mathrm{H}_{12}=1: 20\right)$. The structure of $\mathbf{2 a}$ was confirmed by comparing its ${ }^{1} \mathrm{H}$ - and ${ }^{13} \mathrm{C}$-NMR spectra with previously reported data described in the literature. ${ }^{2}{ }^{1} \mathrm{H}$ NMR $\left(400 \mathrm{MHz}, \mathrm{CDCl}_{3}\right) \delta 8.00-7.91(\mathrm{~m}, 2 \mathrm{H}), 7.61-7.52(\mathrm{~m}, 1 \mathrm{H}), 7.52-7.39(\mathrm{~m}, 2 \mathrm{H})$, $2.61(\mathrm{~s}, 3 \mathrm{H}) \mathrm{ppm} .{ }^{13} \mathrm{C}$ NMR $\left(101 \mathrm{MHz}, \mathrm{CDCl}_{3}\right) \delta$ 198.0, 137.0, 132.9, $128.4(\mathrm{x} 2), 128.1(\mathrm{x} 2), 26.4 \mathrm{ppm}$.<smiles>CC(=O)c1ccc(C(C)(C)C)cc1</smiles>

p-tert-Butylacetophenone (2b). The general procedure was followed from $1 \mathrm{~b}(0.160 \mathrm{~g}, 1 \mathrm{mmol})$ to afford $\mathbf{2 b}(0.132 \mathrm{~g}, 0.75 \mathrm{mmol}, 75 \%$ yield $)$ as colorless oil. $\mathbf{2 b}$ was purified by column chromatography on silica gel, eluting with ethyl acetate cyclohexane mixtures $\left(E t O A c / \mathrm{C}_{6} \mathrm{H}_{12}=1: 20\right)$. The structure of $\mathbf{2 b}$ was confirmed by comparing its ${ }^{1} \mathrm{H}$ - and ${ }^{13} \mathrm{C}$-NMR spectra with previously reported data described in the literature. ${ }^{3}{ }^{1} \mathrm{H}$ NMR $\left(400 \mathrm{MHz}, \mathrm{CDCl}_{3}\right) \delta 7.91(\mathrm{~d}, J=8.5 \mathrm{~Hz}, 2 \mathrm{H}), 7.49(\mathrm{~d}, \mathrm{~J}=8.4 \mathrm{~Hz}, 2 \mathrm{H}), 2.59(\mathrm{~s}$, $3 \mathrm{H}), 1.35(\mathrm{~s}, 9 \mathrm{H}) .{ }^{13} \mathrm{C}$ NMR $\left(101 \mathrm{MHz}, \mathrm{CDCl}_{3}\right) \delta 197.7,156.7,134.6,128.2(\mathrm{x} 2), 125.4(\mathrm{x} 2), 35.0,31.0$ (x3), $26.4 \mathrm{ppm}$.<smiles>CC(=O)c1ccc(C)cc1</smiles>

$$
\text { 2c }
$$

p-Methylacetophenone (2c). The general procedure was followed from $1 \mathrm{c}(0.118 \mathrm{~g}, 1 \mathrm{mmol})$ to afford 2c $(0.106 \mathrm{~g}, 0.79 \mathrm{mmol}, 79 \%$ yield) as colorless oil. $2 \mathrm{c}$ was purified by column chromatography on silica gel, eluting with ethyl acetate cyclohexane mixtures $\left(E t O A c /{ }_{6} \mathrm{H}_{12}=1: 20\right)$. The structure of $2 \mathbf{c}$ was confirmed by comparing its ${ }^{1} \mathrm{H}$ - and ${ }^{13} \mathrm{C}$-NMR spectra with previously reported data described in the 
literature. ${ }^{4}{ }^{1} \mathrm{H}$ NMR $\left(400 \mathrm{MHz}, \mathrm{CDCl}_{3}\right) \delta 7.85(\mathrm{~d}, J=8.2 \mathrm{~Hz}, 2 \mathrm{H}), 7.25(\mathrm{~d}, J=8.0 \mathrm{~Hz}, 2 \mathrm{H}), 2.57(\mathrm{~s}, 3 \mathrm{H})$, 2.40 (s, 3H) ppm. ${ }^{13} \mathrm{C}$ NMR (101 MHz, $\left.\mathrm{CDCl}_{3}\right) \delta$ 197.7, 143.8, 134.6, 129.1 (x2), 128.3 (x2), 26.4, 21.5 ppm.<smiles>CC(=O)c1ccccc1C</smiles>

2d

o-Methylacetophenone (2d). The general procedure was followed from $1 \mathrm{~d}(0.118 \mathrm{~g}, 1 \mathrm{mmol})$ to afford 2d $(0.047 \mathrm{~g}, 0.35 \mathrm{mmol}, 35 \%$ yield) as colorless oil. $2 \mathbf{d}$ was purified by column chromatography on silica gel, eluting with ethyl acetate cyclohexane mixtures $\left(E t O A c / \mathrm{C}_{6} \mathrm{H}_{12}=1: 20\right)$. The structure of $2 \mathbf{d}$ was confirmed by comparing its ${ }^{1} \mathrm{H}$ - and ${ }^{13} \mathrm{C}$-NMR spectra with previously reported data described in the literature..$^{5}{ }^{1} \mathrm{H}$ NMR $\left(400 \mathrm{MHz}, \mathrm{CDCl}_{3}\right) \delta 7.68(\mathrm{dd}, J=7.7,1.4 \mathrm{~Hz}, 1 \mathrm{H}), 7.37(\mathrm{td}, J=7.5,1.4 \mathrm{~Hz}, 1 \mathrm{H})$, $7.30-7.20(\mathrm{~m}, 2 \mathrm{H}), 2.57(\mathrm{~s}, 3 \mathrm{H}), 2.53(\mathrm{~s}, 3 \mathrm{H}) \mathrm{ppm} .{ }^{13} \mathrm{C}$ NMR $\left(101 \mathrm{MHz}, \mathrm{CDCl}_{3}\right) \delta$ 201.6, 138.3, 137.6, $131.9,131.4,129.3,125.6,29.4,21.5 \mathrm{ppm}$.<smiles>CC(=O)c1ccc(F)cc1</smiles>

p-Fluoroacetophenone (2e). The general procedure was followed from $1 \mathrm{e}(0.122 \mathrm{~g}, 1 \mathrm{mmol})$ to afford $2 \mathrm{e}(0.109 \mathrm{~g}, 0.79 \mathrm{mmol}, 79 \%$ yield) as colorless oil. $2 \mathrm{e}$ was purified by column chromatography on silica gel, eluting with ethyl acetate cyclohexane mixtures $\left(E t O A c / \mathrm{C}_{6} \mathrm{H}_{12}=1: 20\right)$. The structure of $2 \mathbf{e}$ was confirmed by comparing its ${ }^{1} \mathrm{H}$ - and ${ }^{13} \mathrm{C}-\mathrm{NMR}$ spectra with previously reported data described in the literature. ${ }^{6}{ }^{1} \mathrm{H}$ NMR $\left(400 \mathrm{MHz}, \mathrm{CDCl}_{3}\right) \delta 7.96(\mathrm{dd}, J=5.3,3.0 \mathrm{~Hz}, 2 \mathrm{H}), 7.10(\mathrm{dd}, J=8.7,3.4 \mathrm{~Hz}, 2 \mathrm{H})$, 2.58 (s, 3H) ppm. ${ }^{13} \mathrm{C} \mathrm{NMR}\left(101 \mathrm{MHz}, \mathrm{CDCl}_{3}\right) \delta 196.3,165.7$ (d, $\left.J=256 \mathrm{~Hz}\right), 133.5$ (d, J = $\left.3 \mathrm{~Hz}\right), 130.9$ $(\mathrm{d}, J=9 \mathrm{~Hz})(\mathrm{x} 2), 115.6(\mathrm{~d}, J=21 \mathrm{~Hz})(\mathrm{x} 2), 26.4 \mathrm{ppm}$.<smiles>CC(=O)c1ccccc1F</smiles>

o-Fluoroacetophenone (2f). The general procedure was followed from $1 \mathrm{f}(0.122 \mathrm{~g}, 1 \mathrm{mmol})$ to afford $2 \mathrm{f}(0.063 \mathrm{~g}, 0.46 \mathrm{mmol}, 46 \%$ yield) as colorless oil. $2 \mathrm{f}$ was purified by column chromatography on silica gel, eluting with ethyl acetate cyclohexane mixtures $\left(E t O A c / C_{6} \mathrm{H}_{12}=1: 20\right)$. The structure of $2 \mathbf{f}$ was confirmed by comparing its ${ }^{1} \mathrm{H}$ - and ${ }^{13} \mathrm{C}$-NMR spectra with previously reported data described in the literature. ${ }^{7}{ }^{1} \mathrm{H}$ NMR $\left(400 \mathrm{MHz}, \mathrm{CDCl}_{3}\right) \delta 7.95-7.79(\mathrm{~m}, 1 \mathrm{H}), 7.52(\mathrm{dq}, J=7.6,2.5 \mathrm{~Hz}, 1 \mathrm{H}), 7.27-7.02$ $(\mathrm{m}, 2 \mathrm{H}), 2.65$ (dd, $J=5.3,3.3 \mathrm{~Hz}, 3 \mathrm{H}) \mathrm{ppm} .{ }^{13} \mathrm{C} \mathrm{NMR}\left(101 \mathrm{MHz}, \mathrm{CDCl}_{3}\right) \delta 195.8,162.2(\mathrm{~d}, J=256 \mathrm{~Hz})$, $134.6(\mathrm{~d}, J=9 \mathrm{~Hz}), 130.5(\mathrm{~d}, J=4 \mathrm{~Hz}), 125.7(\mathrm{~d}, J=13 \mathrm{~Hz}), 124.3(\mathrm{~d}, J=4 \mathrm{~Hz}), 116.7(\mathrm{~d}, J=23 \mathrm{~Hz})$, $31.4(\mathrm{~d}, J=8 \mathrm{~Hz}) \mathrm{ppm}$.<smiles>CC(=O)c1ccc(Cl)cc1</smiles>

p-Chloroacetophenone $(\mathbf{2 g})$. The general procedure was followed from $1 \mathrm{~g}(0.138 \mathrm{~g}, 1 \mathrm{mmol})$ to afford $\mathbf{2 g}(0.134 \mathrm{~g}, 0.87 \mathrm{mmol}, 87 \%$ yield) as colorless oil. $\mathbf{2 g}$ was purified by column chromatography on silica gel, eluting with ethyl acetate cyclohexane mixtures $\left(E t O A c / C_{6} \mathrm{H}_{12}=1: 20\right)$. The structure of $\mathbf{2} \mathbf{g}$ was confirmed by comparing its ${ }^{1} \mathrm{H}$ - and ${ }^{13} \mathrm{C}$-NMR spectra with previously reported data described in the literature. ${ }^{4}{ }^{1} \mathrm{H}$ NMR $\left(400 \mathrm{MHz}, \mathrm{CDCl}_{3}\right) \delta 7.88(\mathrm{~d}, J=8.6 \mathrm{~Hz}, 2 \mathrm{H}), 7.42(\mathrm{~d}, J=8.6 \mathrm{~Hz}, 2 \mathrm{H}), 2.58(\mathrm{~s}, 3 \mathrm{H})$ ppm. ${ }^{13} \mathrm{C}$ NMR (101 MHz, $\left.\mathrm{CDCl}_{3}\right) \delta$ 196.6, 139.4, 135.3, 129.6 (x2), 128.7 (x2), 26.4 ppm. 
<smiles>CC(=O)c1ccccc1Cl</smiles>

$2 \mathrm{~h}$

o-Chloroacetophenone $(2 \mathrm{~h})$. The general procedure was followed from $1 \mathrm{~h}(0.138 \mathrm{~g}, 1 \mathrm{mmol})$ to afford $2 \mathrm{~h}(0.082 \mathrm{~g}, 0.53 \mathrm{mmol}, 53 \%$ yield) as colorless oil. $2 \mathrm{~h}$ was purified by column chromatography on silica gel, eluting with ethyl acetate cyclohexane mixtures (EtOAc/ $\left.\mathrm{C}_{6} \mathrm{H}_{12}=1: 20\right)$. The structure of $\mathbf{2} \boldsymbol{h}$ was confirmed by comparing its ${ }^{1} \mathrm{H}$ - and ${ }^{13} \mathrm{C}$-NMR spectra with previously reported data described in the literature. ${ }^{5}{ }^{1} \mathrm{H}$ NMR $\left(400 \mathrm{MHz}, \mathrm{CDCl}_{3}\right) \delta 7.55$ (ddd, $\left.J=7.6,1.7,0.6 \mathrm{~Hz}, 1 \mathrm{H}\right), 7.45-7.26(\mathrm{~m}, 3 \mathrm{H}), 2.64$ (s, 3H) ppm. ${ }^{13} \mathrm{C}$ NMR $\left(101 \mathrm{MHz}, \mathrm{CDCl}_{3}\right) \delta 200.3,139.1,131.9,131.2,130.6,129.3,126.8,30.6 \mathrm{ppm}$.<smiles>CC(=O)c1ccc(Br)cc1</smiles>

p-Bromoacetophenone (2i). The general procedure was followed from $1 \mathbf{i}(0.183 \mathrm{~g}, 1 \mathrm{mmol})$ to afford $2 \mathbf{i}(0.149 \mathrm{~g}, 0.75 \mathrm{mmol}, 75 \%$ yield) as colorless oil. $2 \mathbf{i}$ was purified by column chromatography on silica gel, eluting with ethyl acetate cyclohexane mixtures $\left(E t O A c / C_{6} \mathrm{H}_{12}=1: 20\right)$. The structure of $2 \mathbf{i}$ was confirmed by comparing its ${ }^{1} \mathrm{H}$ - and ${ }^{13} \mathrm{C}$-NMR spectra with previously reported data described in the literature. ${ }^{8}{ }^{1} \mathrm{H}$ NMR $\left(400 \mathrm{MHz}, \mathrm{CDCl}_{3}\right) \delta 7.81(\mathrm{~d}, J=8.6 \mathrm{~Hz}, 2 \mathrm{H}), 7.60(\mathrm{~d}, J=8.6 \mathrm{~Hz}, 2 \mathrm{H}), 2.58(\mathrm{~s}, 3 \mathrm{H})$ ppm. ${ }^{13} \mathrm{C}$ NMR (101 MHz, $\left.\mathrm{CDCl}_{3}\right) \delta 196.9,135.8,131.8(x 2), 129.8$ (x2), 128.2, $26.5 \mathrm{ppm}$.

Known compound. ${ }^{7}$<smiles>CC(=O)c1cccc(Br)c1</smiles>

2j

$m$-Bromoacetophenone $(2 \mathrm{j})$. The general procedure was followed from $1 \mathrm{j}(0.183 \mathrm{~g}, 1 \mathrm{mmol})$ to afford $2 \mathbf{i}(0.140 \mathrm{~g}, 0.70 \mathrm{mmol}, 70 \%$ yield) as colorless oil. $2 \mathbf{j}$ was purified by column chromatography on silica gel, eluting with ethyl acetate cyclohexane mixtures $\left(E t O A c / C_{6} \mathrm{H}_{12}=1: 20\right)$. The structure of $2 \mathbf{i}$ was confirmed by comparing its ${ }^{1} \mathrm{H}$ - and ${ }^{13} \mathrm{C}$-NMR spectra with previously reported data described in the literature. ${ }^{7}{ }^{1} \mathrm{H}$ NMR $\left(400 \mathrm{MHz}, \mathrm{CDCl}_{3}\right) \delta 8.08(\mathrm{t}, J=1.9 \mathrm{~Hz}, 1 \mathrm{H}), 7.94-7.85(\mathrm{~m}, 1 \mathrm{H}), 7.69$ (ddd, $J=8.0$, 2.0, $1.0 \mathrm{~Hz}, 1 \mathrm{H}), 7.35(\mathrm{t}, J=7.9 \mathrm{~Hz}, 1 \mathrm{H}), 2.60(\mathrm{~s}, 3 \mathrm{H}) \mathrm{ppm} .{ }^{13} \mathrm{C}$ NMR $\left(101 \mathrm{MHz}, \mathrm{CDCl}_{3}\right) \delta 196.5,138.7$, $135.8,131.2,130.1,126.7,122.8,26.5 \mathrm{ppm}$.<smiles>CC(=O)c1ccc(C(F)(F)F)cc1</smiles>

p-Trifluoromethylacetophenone (2k). The general procedure was followed from $1 \mathbf{k}(0.172 \mathrm{~g}, 1 \mathrm{mmol})$ to afford $2 \mathbf{k}(0.128 \mathrm{~g}, 0.68 \mathrm{mmol}, 68 \%$ yield) as colorless oil. $2 \mathbf{k}$ was purified by column chromatography on silica gel with pentane/DCM (4:1), and further purified by Kugelrohr distillation. The structure of $\mathbf{2 k}$ was confirmed by comparing its ${ }^{1} \mathrm{H}$ - and ${ }^{13} \mathrm{C}$-NMR spectra with previously reported data described in the literature. ${ }^{9}{ }^{1} \mathrm{H}$ NMR $\left(400 \mathrm{MHz}, \mathrm{CDCl}_{3}\right) \delta 8.09-7.98(\mathrm{~m}, 2 \mathrm{H}), 7.79-7.62(\mathrm{~m}, 2 \mathrm{H}), 2.65(\mathrm{~s}, 3 \mathrm{H}) \mathrm{ppm}$. ${ }^{13} \mathrm{C}$ NMR $\left(101 \mathrm{MHz}, \mathrm{CDCl}_{3}\right) \delta 196.9,139.7,134.4$ (q, $\left.J=33 \mathrm{~Hz}\right), 128.6(x 2), 125.6(\mathrm{q}, J=4 \mathrm{~Hz})(\mathrm{x} 2)$, 123.6 (q, $J=271 \mathrm{~Hz}$ ), $26.7 \mathrm{ppm}$.<smiles>CC(=O)c1cccc(C(F)(F)F)c1</smiles> 
$\boldsymbol{m}$-Trifluoromethylacetophenone (2I). The general procedure was followed from $1 \mathrm{l}(0.172 \mathrm{~g}, 1 \mathrm{mmol})$ to afford $2 \mathrm{I}(0.135 \mathrm{~g}, 0.72 \mathrm{mmol}, 72 \%$ yield) as colorless oil. $2 \mathrm{I}$ was purified by column chromatography on silica gel, eluting with ethyl acetate cyclohexane mixtures $\left(E t O A c / C_{6} \mathrm{H}_{12}=1: 20\right)$. The structure of 2 I was confirmed by comparing its ${ }^{1} \mathrm{H}$ - and ${ }^{13} \mathrm{C}-\mathrm{NMR}$ spectra with previously reported data described in the literature..$^{10}{ }^{1} \mathrm{H}$ NMR $\left(400 \mathrm{MHz}, \mathrm{CDCl}_{3}\right) \delta 8.27-8.08(\mathrm{~m}, 2 \mathrm{H}), 7.87-7.74(\mathrm{~m}, 1 \mathrm{H}), 7.68-7.51(\mathrm{~m}$, $1 \mathrm{H}), 2.64(\mathrm{~d}, J=0.8 \mathrm{~Hz}, 3 \mathrm{H}) \mathrm{ppm} .{ }^{13} \mathrm{C}$ NMR $\left(101 \mathrm{MHz}, \mathrm{CDCl}_{3}\right) \delta 196.5,137.5,131.4,131.3$ (q, $J=33$ $\mathrm{Hz}), 129.5(\mathrm{q}, J=4 \mathrm{~Hz}), 129.3,125.1(\mathrm{q}, J=5 \mathrm{~Hz}), 123.7(\mathrm{q}, J=271 \mathrm{~Hz}), 26.5 \mathrm{ppm}$.<smiles>COc1cccc(C(C)=O)c1</smiles>

$m$-Methoxyacetophenone $(2 \mathrm{~m})$. The general procedure was followed from $1 \mathrm{~m}(0.134 \mathrm{~g}, 1 \mathrm{mmol})$ to afford $2 \mathrm{~m}(0.049 \mathrm{~g}, 0.33 \mathrm{mmol}, 33 \%$ yield) as colorless oil. $2 \mathrm{~m}$ was purified by column chromatography on silica gel, eluting with ethyl acetate cyclohexane mixtures $\left(E t O A c / \mathrm{C}_{6} \mathrm{H}_{12}=1: 5\right)$. The structure of $\mathbf{2 m}$ was confirmed by comparing its ${ }^{1} \mathrm{H}$ - and ${ }^{13} \mathrm{C}-\mathrm{NMR}$ spectra with previously reported data described in the literature..$^{11}{ }^{1} \mathrm{H}$ NMR $\left(400 \mathrm{MHz}, \mathrm{CDCl}_{3}\right) \delta 7.57-7.44(\mathrm{~m}, 2 \mathrm{H}), 7.36$ (ddd, $\left.J=8.2,7.6,0.4 \mathrm{~Hz}, 1 \mathrm{H}\right)$, 7.10 (ddd, $J=8.2,2.7,1.0 \mathrm{~Hz}, 1 \mathrm{H}), 3.85(\mathrm{~s}, 3 \mathrm{H}), 2.59(\mathrm{~s}, 3 \mathrm{H}) \mathrm{ppm} .{ }^{13} \mathrm{C} \mathrm{NMR}\left(101 \mathrm{MHz}, \mathrm{CDCl}_{3}\right) \delta 197.8$, $159.7,138.4,129.5,121.0,119.5,112.3,55.3,26.6 \mathrm{ppm}$.<smiles>CCOC(=O)c1ccc(C(C)=O)cc1</smiles>

p-Methoxycarbonylacetophenone (2n). The general procedure was followed from $1 \mathrm{n}(0.176 \mathrm{~g}, 1$ $\mathrm{mmol})$ to afford $2 \mathrm{n}(0.138 \mathrm{~g}, 0.72 \mathrm{mmol}, 72 \%$ yield $)$ as white solid. $2 \mathrm{n}$ was purified by column chromatography on silica gel, eluting with ethyl acetate cyclohexane mixtures $\left(\mathrm{EtOAc} / \mathrm{C}_{6} \mathrm{H}_{12}=1: 10\right)$. The structure of $2 n$ was confirmed by comparing its ${ }^{1} \mathrm{H}$ - and ${ }^{13} \mathrm{C}-\mathrm{NMR}$ spectra with previously reported data described in the literature. ${ }^{12}{ }^{1} \mathrm{H}$ NMR $\left(400 \mathrm{MHz}, \mathrm{CDCl}_{3}\right) \delta 8.13(\mathrm{~d}, J=8.7 \mathrm{~Hz}, 2 \mathrm{H}), 8.01(\mathrm{~d}, J=8.7$ $\mathrm{Hz}, 2 \mathrm{H}), 3.95(\mathrm{~s}, 3 \mathrm{H}), 2.65(\mathrm{~s}, 3 \mathrm{H}) \mathrm{ppm} .{ }^{13} \mathrm{C}$ NMR $\left(101 \mathrm{MHz}, \mathrm{CDCl}_{3}\right) \delta 197.5,166.2,140.2,133.9,129.8$, $128.17,52.4,26.8 \mathrm{ppm}$.<smiles>CC(=O)c1cccc(C)c1</smiles>

20

$\boldsymbol{m}$-Methylacetophenone (2o). The general procedure was followed from $1 \mathrm{n}(0.118 \mathrm{~g}, 1 \mathrm{mmol})$ to afford 2n $(0.093 \mathrm{~g}, 0.69 \mathrm{mmol}, 69 \%$ yield) as colorless oil. 20 was purified by column chromatography on silica gel, eluting with ethyl acetate cyclohexane mixtures $\left(E t O A c / \mathrm{C}_{6} \mathrm{H}_{12}=1: 20\right)$. The structure of $2 \mathbf{n}$ was confirmed by comparing its ${ }^{1} \mathrm{H}$ - and ${ }^{13} \mathrm{C}$-NMR spectra with previously reported data described in the literature. ${ }^{6}{ }^{1} \mathrm{H}$ NMR $\left(400 \mathrm{MHz}, \mathrm{CDCl}_{3}\right) \delta 7.81-7.68(\mathrm{~m}, 2 \mathrm{H}), 7.39-7.30(\mathrm{~m}, 2 \mathrm{H}), 2.58(\mathrm{~s}, 3 \mathrm{H}), 2.40(\mathrm{~s}$, $3 \mathrm{H}) \mathrm{ppm} .{ }^{13} \mathrm{C}$ NMR $\left(101 \mathrm{MHz}, \mathrm{CDCl}_{3}\right) \delta 198.2,138.2,137.1,133.7,128.7,128.3,125.5,26.5,21.2$ ppm.<smiles>CCC(=O)c1ccccc1</smiles>

$2 p$

Propiophenone (2p). The general procedure was followed from $(E)-10$ or $(Z)-10(0.118 \mathrm{~g}, 1 \mathrm{mmol}$ in each case) to afford 20 [0.078 g, $0.58 \mathrm{mmol}, 58 \%$ yield from $(E)-10$ or $0.087 \mathrm{~g}, 0.65 \mathrm{mmol}, 65 \%$ yield from (Z)-10] as colorless oil. $2 p$ was purified by column chromatography on silica gel, eluting with ethyl acetate cyclohexane mixtures $\left(E t O A c / C_{6} \mathrm{H}_{12}=1: 20\right)$. The structure of $\mathbf{2} \mathbf{n}$ was confirmed by comparing 
its ${ }^{1} \mathrm{H}$ - and ${ }^{13} \mathrm{C}$-NMR spectra with previously reported data described in the literature. ${ }^{13}{ }^{1} \mathrm{H}$ NMR (400 $\left.\mathrm{MHz}, \mathrm{CDCl}_{3}\right) \delta 8.02-7.89(\mathrm{~m}, 2 \mathrm{H}), 7.58-7.48(\mathrm{~m}, 1 \mathrm{H}), 7.50-7.37(\mathrm{~m}, 2 \mathrm{H}), 3.00(\mathrm{qd}, J=7.2,0.9 \mathrm{~Hz}$, $2 \mathrm{H}), 1.22$ (td, $J=7.2,0.6 \mathrm{~Hz}, 3 \mathrm{H}) \mathrm{ppm} .{ }^{13} \mathrm{C}$ NMR $\left(101 \mathrm{MHz}, \mathrm{CDCl}_{3}\right) \delta 200.7,136.9,132.8,128.5(\mathrm{x} 2)$, $127.9(\mathrm{x} 2), 31.7,8.2 \mathrm{ppm}$.<smiles>O=C1CCc2ccccc21</smiles>

$2 q$

1-Indanone (2p). The general procedure was followed from indene (1p) $(0.116 \mathrm{~g}, 1 \mathrm{mmol})$ to afford $\mathbf{2 p}$ $(0.079 \mathrm{~g}, 0.60 \mathrm{mmol}, 60 \%$ yield) as colorless oil. $2 \mathrm{q}$ was purified by column chromatography on silica gel, eluting with ethyl acetate cyclohexane mixtures $\left(E t O A c / C_{6} \mathrm{H}_{12}=1: 20\right)$. The structure of $2 p$ was confirmed by comparing its ${ }^{1} \mathrm{H}$ - and ${ }^{13} \mathrm{C}$-NMR spectra with previously reported data described in the literature..$^{14}{ }^{1} \mathrm{H}$ NMR $\left(400 \mathrm{MHz}, \mathrm{CDCl}_{3}\right) \delta 7.76(\mathrm{~d}, J=7.7 \mathrm{~Hz}, 1 \mathrm{H}), 7.59(\mathrm{td}, J=7.4,1.3 \mathrm{~Hz}, 1 \mathrm{H}), 7.48$ $(\mathrm{dt}, J=7.7,1.0 \mathrm{~Hz}, 1 \mathrm{H}), 7.41-7.34(\mathrm{~m}, 1 \mathrm{H}), 3.20-3.09(\mathrm{~m}, 2 \mathrm{H}), 2.72-2.63(\mathrm{~m}, 2 \mathrm{H}) \mathrm{ppm} .{ }^{13} \mathrm{C}$ NMR $\left(101 \mathrm{MHz}, \mathrm{CDCl}_{3}\right) \delta$ 206.9, 155.1, 137.0, 134.5, 127.2, 126.6, 123.6, 36.1, $25.7 \mathrm{ppm}$.<smiles>O=C(Cc1ccccc1)c1ccccc1</smiles>

$2 r$

1,2-Diphenylethan-1-one (2r). The general procedure was followed from $(E)-1 \mathbf{r}(0.180 \mathrm{~g}, 1 \mathrm{mmol})$ to afford $2 \mathrm{r}(0.096 \mathrm{~g}, 0.49 \mathrm{mmol}, 49 \%$ yield) as white solid. $2 \mathrm{r}$ was purified by column chromatography on silica gel, eluting with ethyl acetate cyclohexane mixtures $\left(\mathrm{EtOAc} / \mathrm{C}_{6} \mathrm{H}_{12}=1: 20\right)$. The structure of $2 \mathrm{r}$ was confirmed by comparing its ${ }^{1} \mathrm{H}$ - and ${ }^{13} \mathrm{C}-\mathrm{NMR}$ spectra with previously reported data described in the literature..$^{15}{ }^{1} \mathrm{H}$ NMR $\left(400 \mathrm{MHz}, \mathrm{CDCl}_{3}\right) \delta 8.00(\mathrm{dd}, J=8.3,1.4 \mathrm{~Hz}, 2 \mathrm{H}), 7.56-7.37(\mathrm{~m}, 3 \mathrm{H}), 7.36-7.17$ $(\mathrm{m}, 5 \mathrm{H}), 4.27$ (s, 2H) ppm. ${ }^{13} \mathrm{C}$ NMR $\left(101 \mathrm{MHz}, \mathrm{CDCl}_{3}\right) \delta$ 197.6, 136.5, 134.5, 133.1, 130.1, 129.4, 128.6, 128.6, 128.5, 128.4, 126.8, $45.4 \mathrm{ppm}$.<smiles>O=C1CCCc2ccccc21</smiles>

2s

1-Tetralone (2s). The general procedure was followed from $1 \mathrm{~s}(0.130 \mathrm{~g}, 1 \mathrm{mmol})$ to afford $2 \mathrm{~s}(0.080 \mathrm{~g}$, $0.55 \mathrm{mmol}, 55 \%$ yield) as colorless oil. $2 \mathrm{~s}$ was purified by column chromatography on silica gel, eluting with ethyl acetate cyclohexane mixtures $\left(E t O A c / C_{6} \mathrm{H}_{12}=1: 20\right)$. The structure of $2 \mathbf{s}$ was confirmed by comparing its ${ }^{1} \mathrm{H}$ - and ${ }^{13} \mathrm{C}-\mathrm{NMR}$ spectra with previously reported data described in the literature.$^{4}{ }^{1} \mathrm{H}$ NMR $\left(400 \mathrm{MHz}, \mathrm{CDCl}_{3}\right) \delta 8.02$ (dd, $\left.J=7.9,1.5 \mathrm{~Hz}, 1 \mathrm{H}\right), 7.46(\mathrm{td}, J=7.5,1.5 \mathrm{~Hz}, 1 \mathrm{H}), 7.33-7.18(\mathrm{~m}$, $2 \mathrm{H}), 2.95(\mathrm{t}, J=6.1 \mathrm{~Hz}, 2 \mathrm{H}), 2.64(\mathrm{dd}, J=7.3,5.9 \mathrm{~Hz}, 2 \mathrm{H}), 2.13(\mathrm{tt}, J=7.4,5.7 \mathrm{~Hz}, 2 \mathrm{H}) \mathrm{ppm} .{ }^{13} \mathrm{C}$ NMR $\left(101 \mathrm{MHz}, \mathrm{CDCl}_{3}\right) \delta 198.3,144.4,133.3,132.5,128.7,127.0,126.5,39.0,29.6,23.2 \mathrm{ppm}$.<smiles>O=C1CCOc2ccccc21</smiles>

2t

4-Chromanone (2t). The general procedure was followed from $1 \mathbf{t}(0.132 \mathrm{~g}, 1 \mathrm{mmol})$ to afford $\mathbf{2 t}(0.070$ $\mathrm{g}, 0.47 \mathrm{mmol}, 47 \%$ yield) as white solid. $2 \mathrm{t}$ was purified by column chromatography on silica gel, eluting with ethyl acetate cyclohexane mixtures $\left(\mathrm{EtOAc} / \mathrm{C}_{6} \mathrm{H}_{12}=1: 20\right)$. The structure of $\mathbf{2} \mathbf{t}$ was confirmed by comparing its ${ }^{1} \mathrm{H}$ - and ${ }^{13} \mathrm{C}-\mathrm{NMR}$ spectra with previously reported data described in the literature. ${ }^{16}{ }^{1} \mathrm{H}$ NMR $\left(400 \mathrm{MHz}, \mathrm{CDCl}_{3}\right) \delta 7.89$ (ddd, $J=7.9,1.8,0.5 \mathrm{~Hz}, 1 \mathrm{H}$ ), 7.47 (ddd, $\left.J=8.3,7.2,1.8 \mathrm{~Hz}, 1 \mathrm{H}\right), 7.06$ $-6.94(\mathrm{~m}, 2 \mathrm{H}), 4.56-4.50(\mathrm{~m}, 2 \mathrm{H}), 2.85-2.78(\mathrm{~m}, 2 \mathrm{H}) \mathrm{ppm} .{ }^{13} \mathrm{C} \mathrm{NMR}\left(101 \mathrm{MHz}, \mathrm{CDCl}_{3}\right) \delta 191.7$, $161.8,135.9,127.1,121.3,117.8,66.9,37.7 \mathrm{ppm}$. 


\section{References}

1. de Boer, J. W.; Browne, W. R.; Harutyunyan, S. R.; Bini, L.; Tiemersma-Wegman, T. D.; Alsters, P. L.; Hage, R.; Feringa, B. L. Chem. Commun. 2008, 3747-3749.

2. Yuan, Y.; Shi, X.; Liu, W. Synlett, 2011, 559-564.

3. Nobuta, T.; Hirashima, S. I.; Tada, N.; Miura, T.; Itoh, A. Org. Lett. 2011, 13, 2576-2579.

4. Cunningham, A.; Mokal-Parekh, V.; Wilson, C.; Woodward, S. Org. Biomol. Chem. 2004, 2, 741748.

5. Ruan, J.; Li, X.; Saidi, O.; Xiao, J. J. Am. Chem. Soc. 2008, 130, 2424-2425.

6. Murphy, J. A.; Commeureuc, A. G. J.; Snaddon, T. N.; McGuire, T. M.; Khan, T. A.; Hisler, K.; Dewis, M. L.; Carling, R. Org. Lett. 2005, 7, 1427-1429.

7. Genna, D. T.; Posner, G. H. Org. Lett. 2011, 13, 5358-5361.

8. Scheiper, B.; Bonnekessel, M.; Krause, H.; Fuerstner, A. J. Org. Chem. 2004, 69, 3943-3949.

9. Chu, L.; Qing, F. -L. Org. Lett. 2010, 12, 5060-5063.

10. Schultz, M. J.; Hamilton, St. S.; Jensen, D. R.; Sigman, M. S. J. Org. Chem. 2005, 70, 3343-3352.

11. Liu, M.; Hyder, Z.; Sun, Y.; Tang, W.; Xu, L.; Xiao, J. Org. Biomol. Chem. 2010, 8, 2012-2015.

12. Liu, S.; Berry, N.; Thomson, N.; Pettman, A.; Hyder, Z.; Mo, J.; Xiao, J. J. Org. Chem. 2006, 71, 7467-7470.

13. (a) Zhao, B.; Lu, X. Tetrahedron Lett. 2006, 47, 6765-6768; (b) linuma, M.; Moriyama, K.; Togo, H. Tetrahedron 2013, 69, 2961-2970.

14. Dohi, T.; Takenaga, N.; Goto, A.; Fujioka, H.; Kita, Y. J. Org. Chem. 2008, 73, 7365-7368.

15. Zhao, B.; Lu, X. Org. Lett. 2006, 8, 5987-5990.

16. Kotani, S.; Osakama, K.; Sugiura, M.; Nakajima, M. Org. Lett. 2011, 13, 3968-3971. 


\section{NMR Spectra}

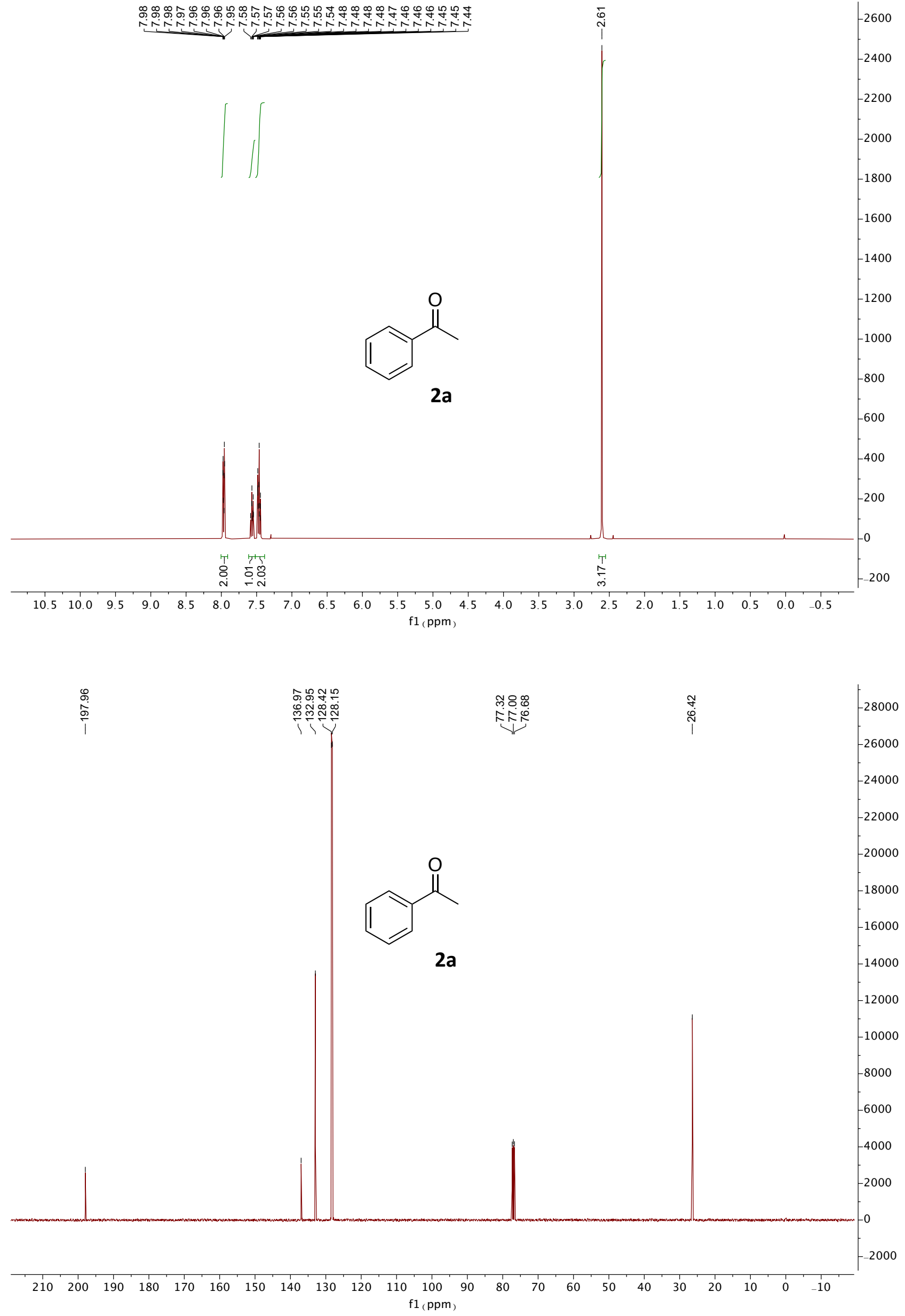



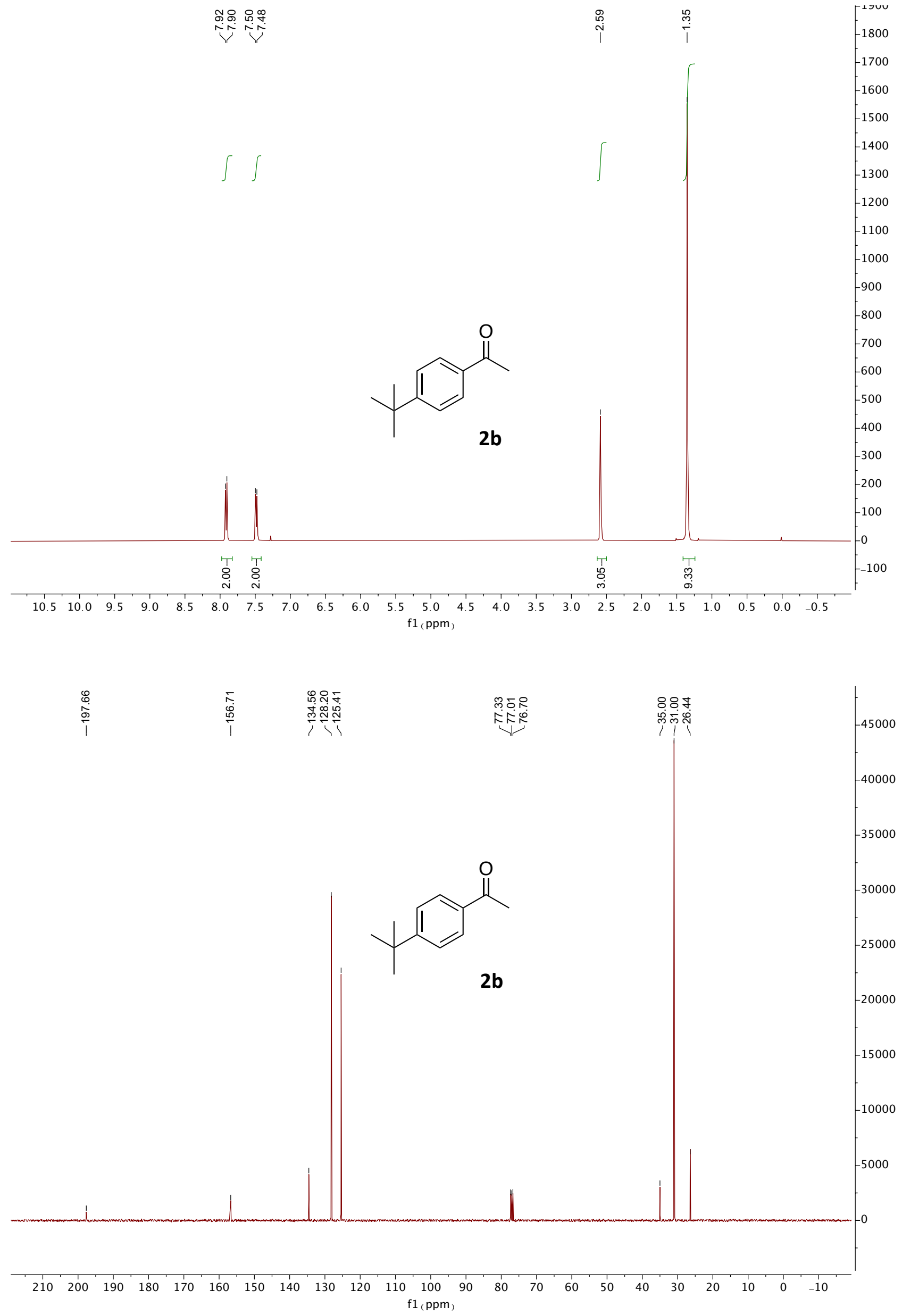

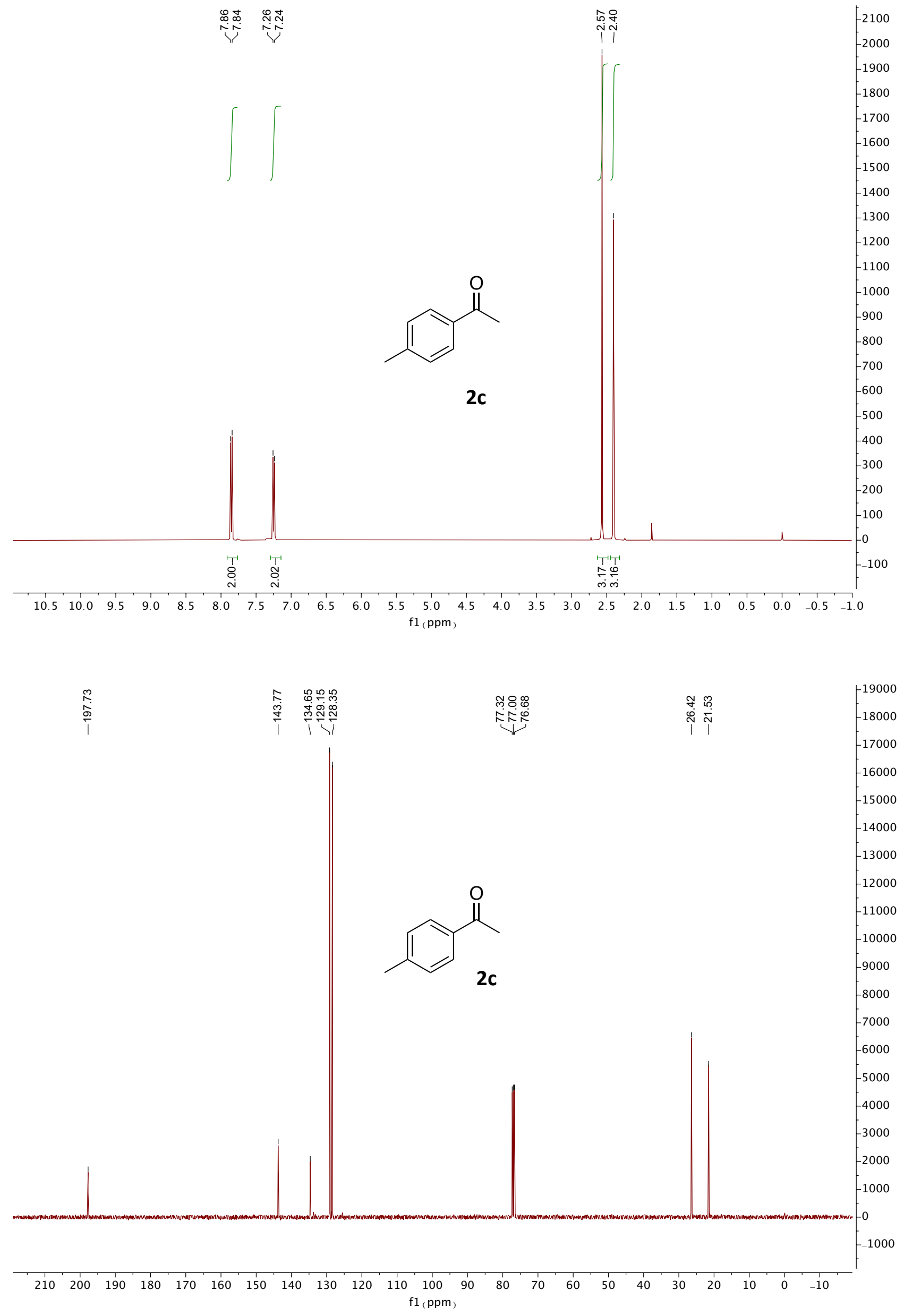


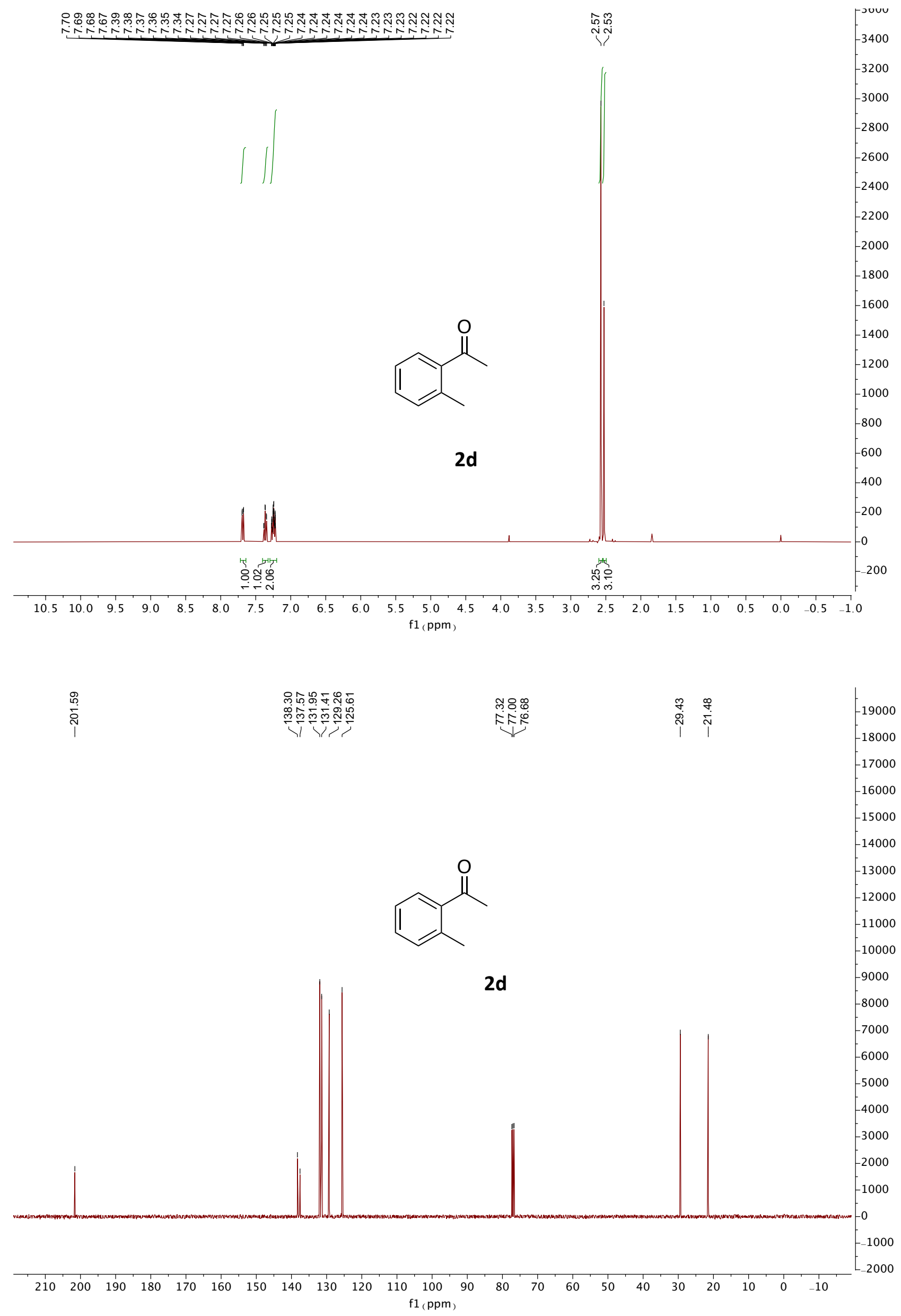




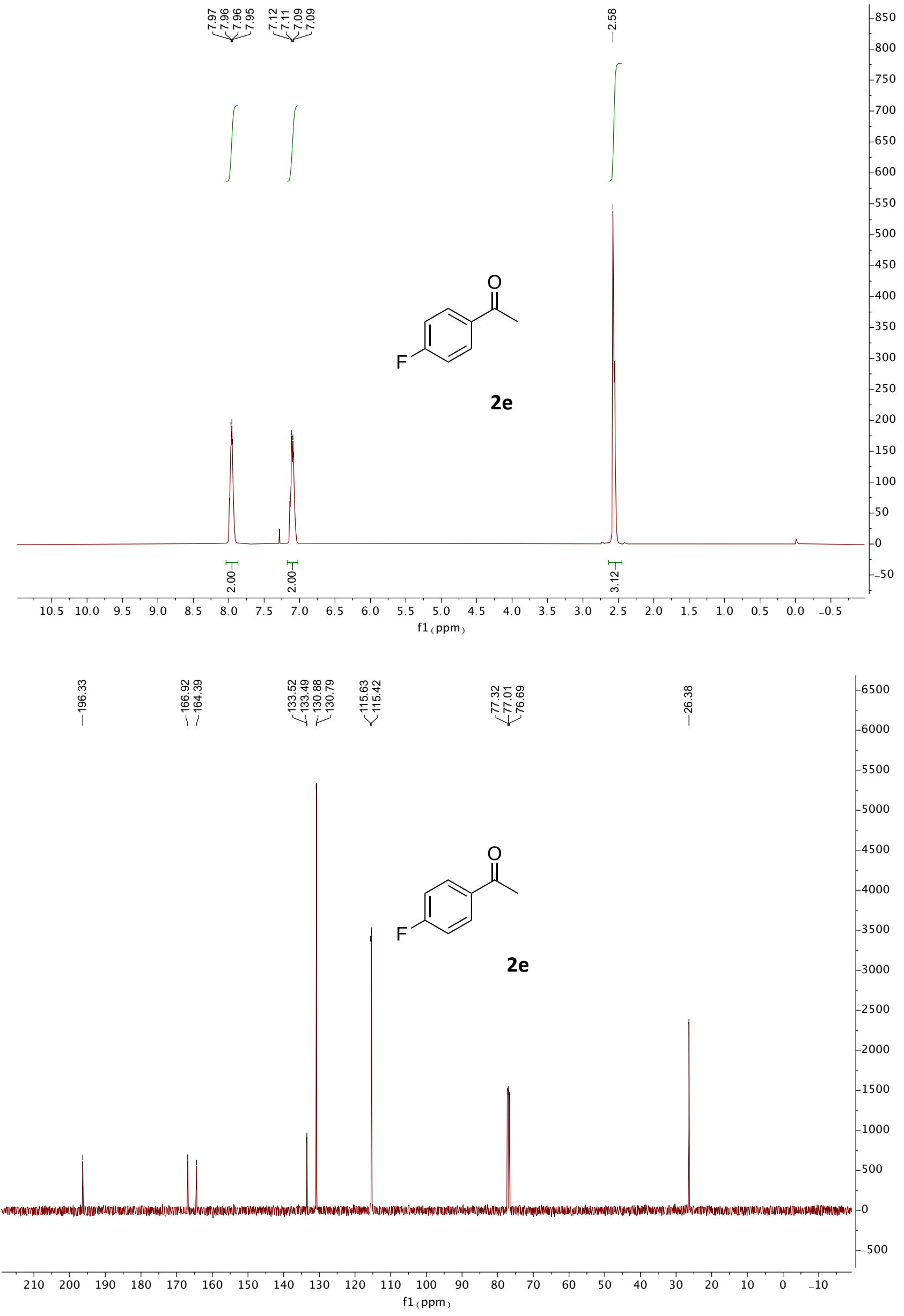



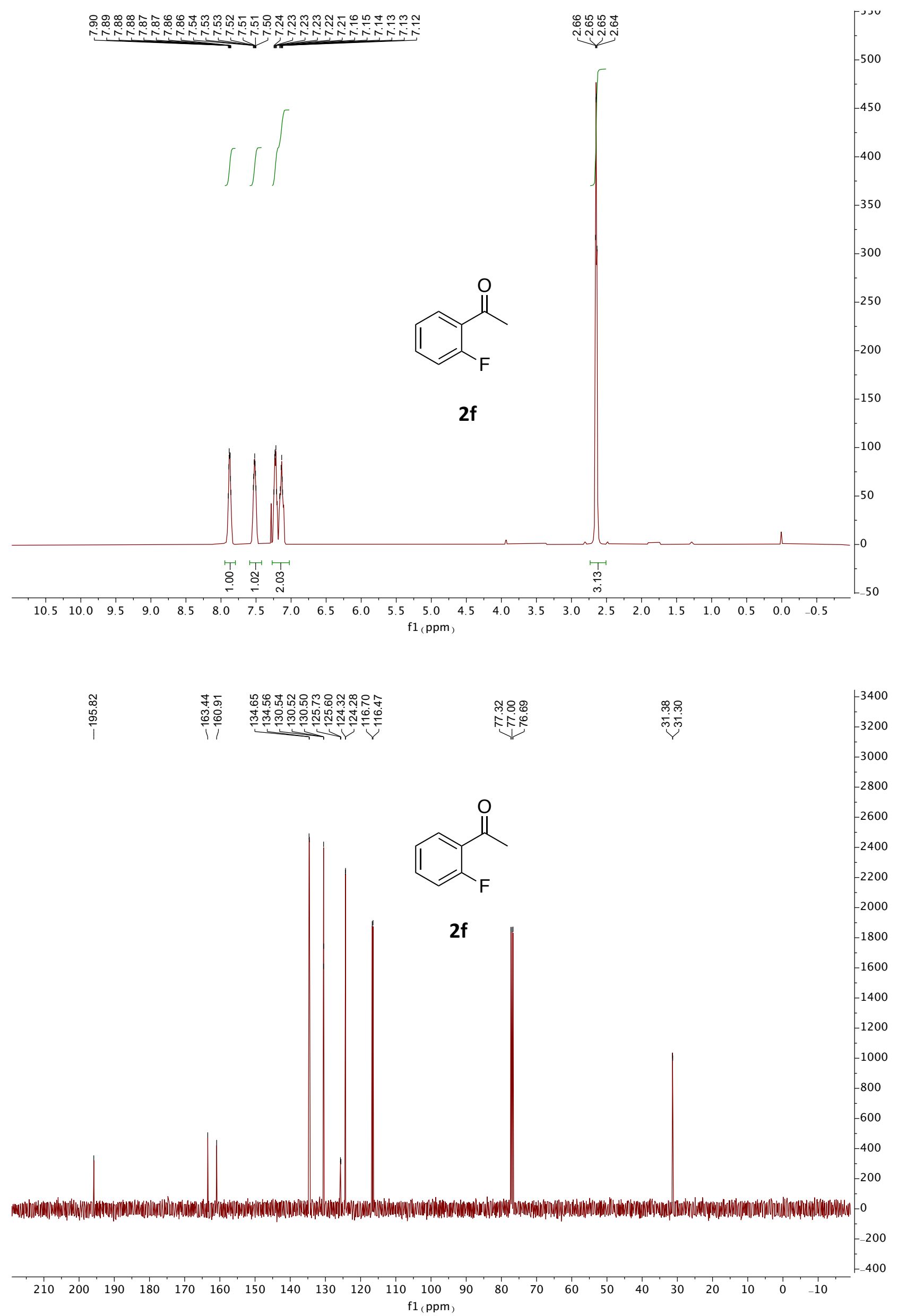


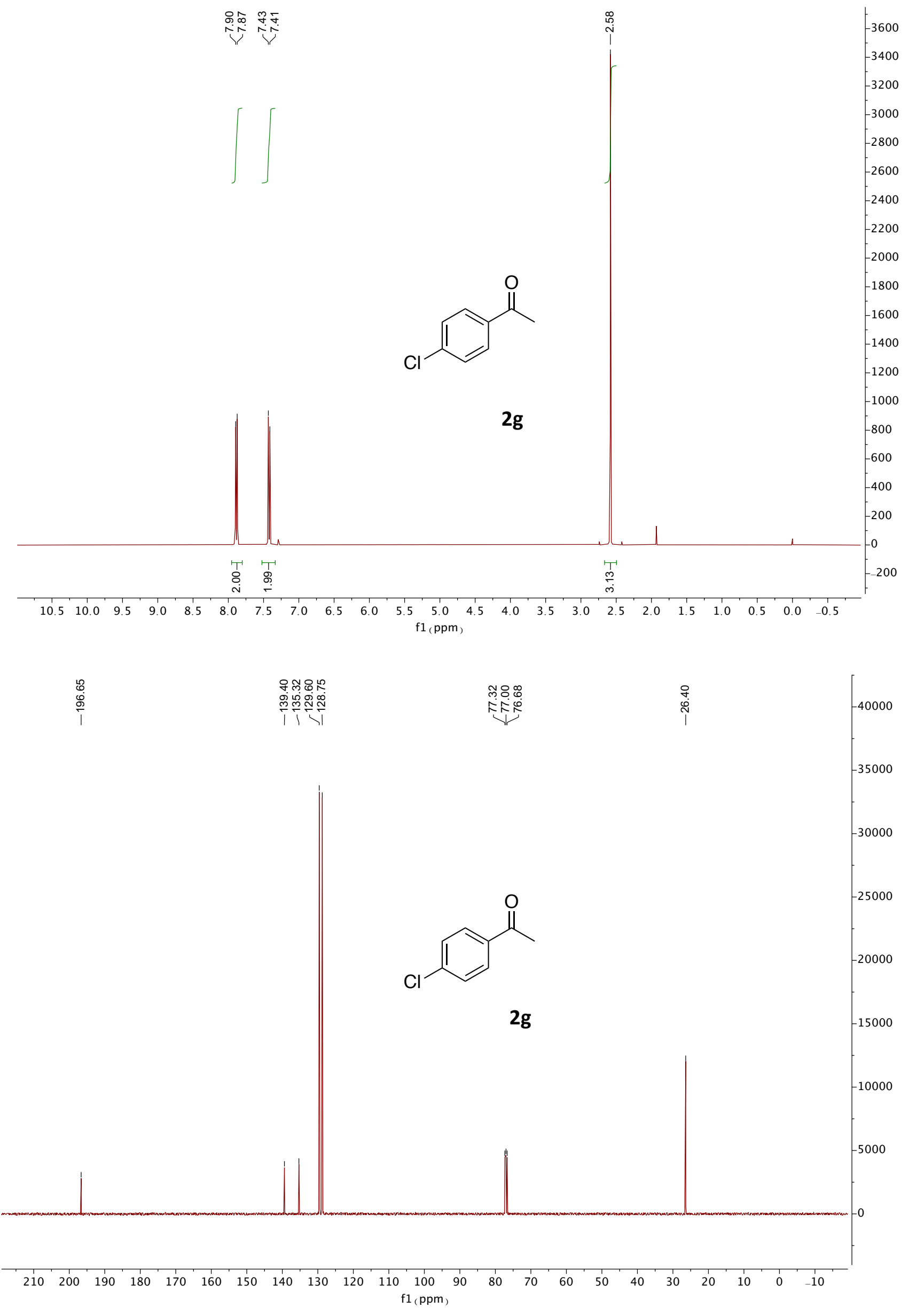




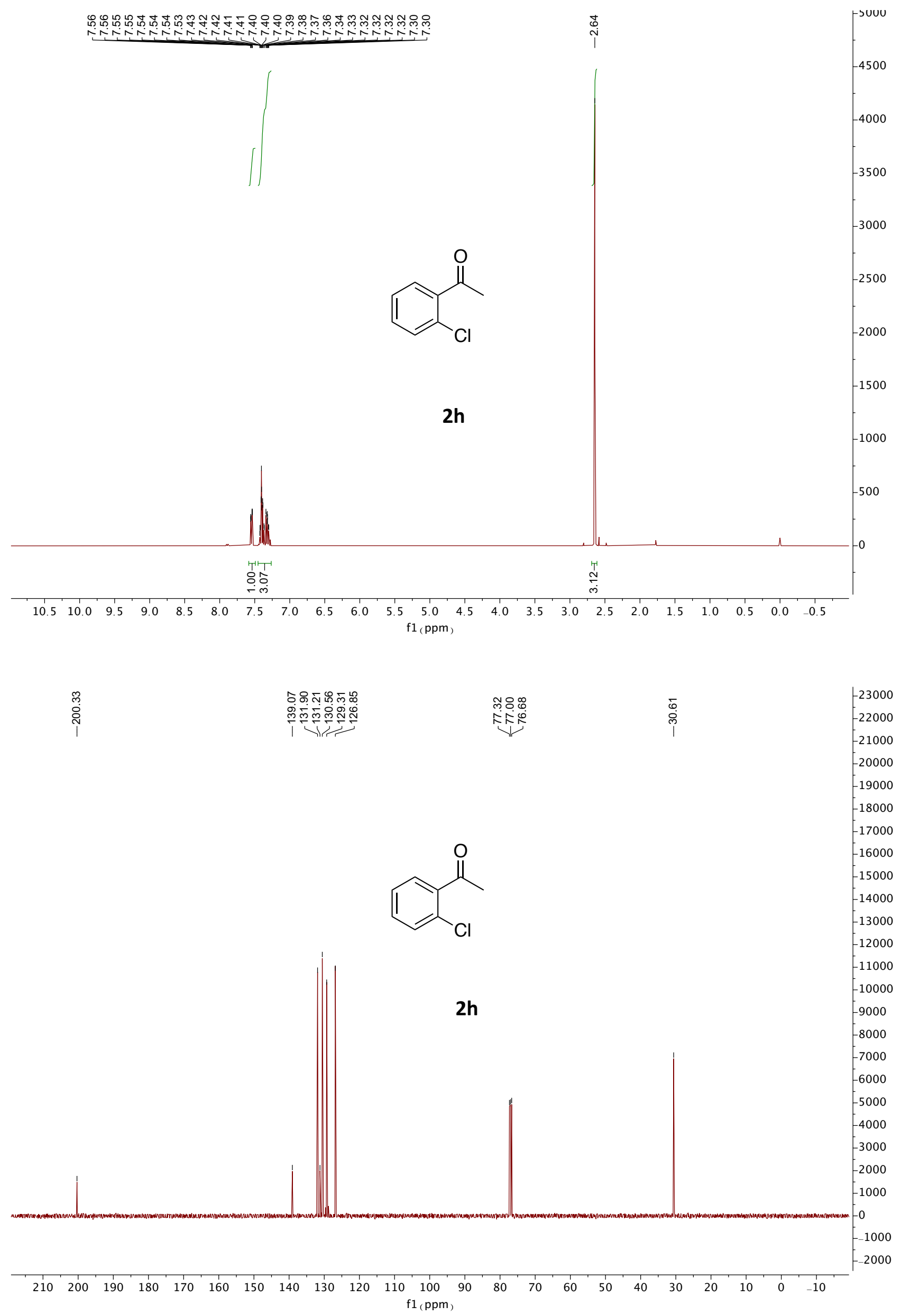




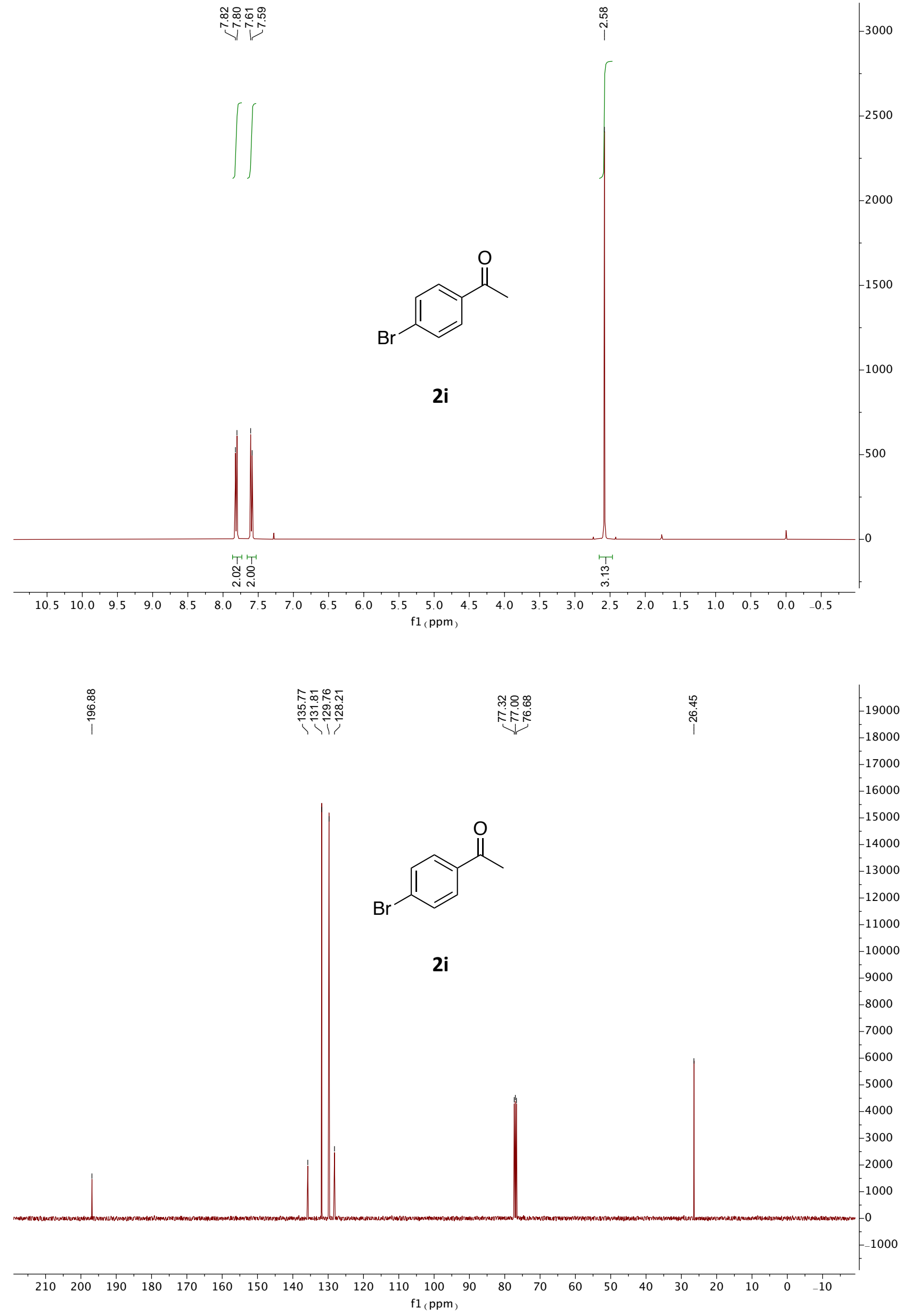




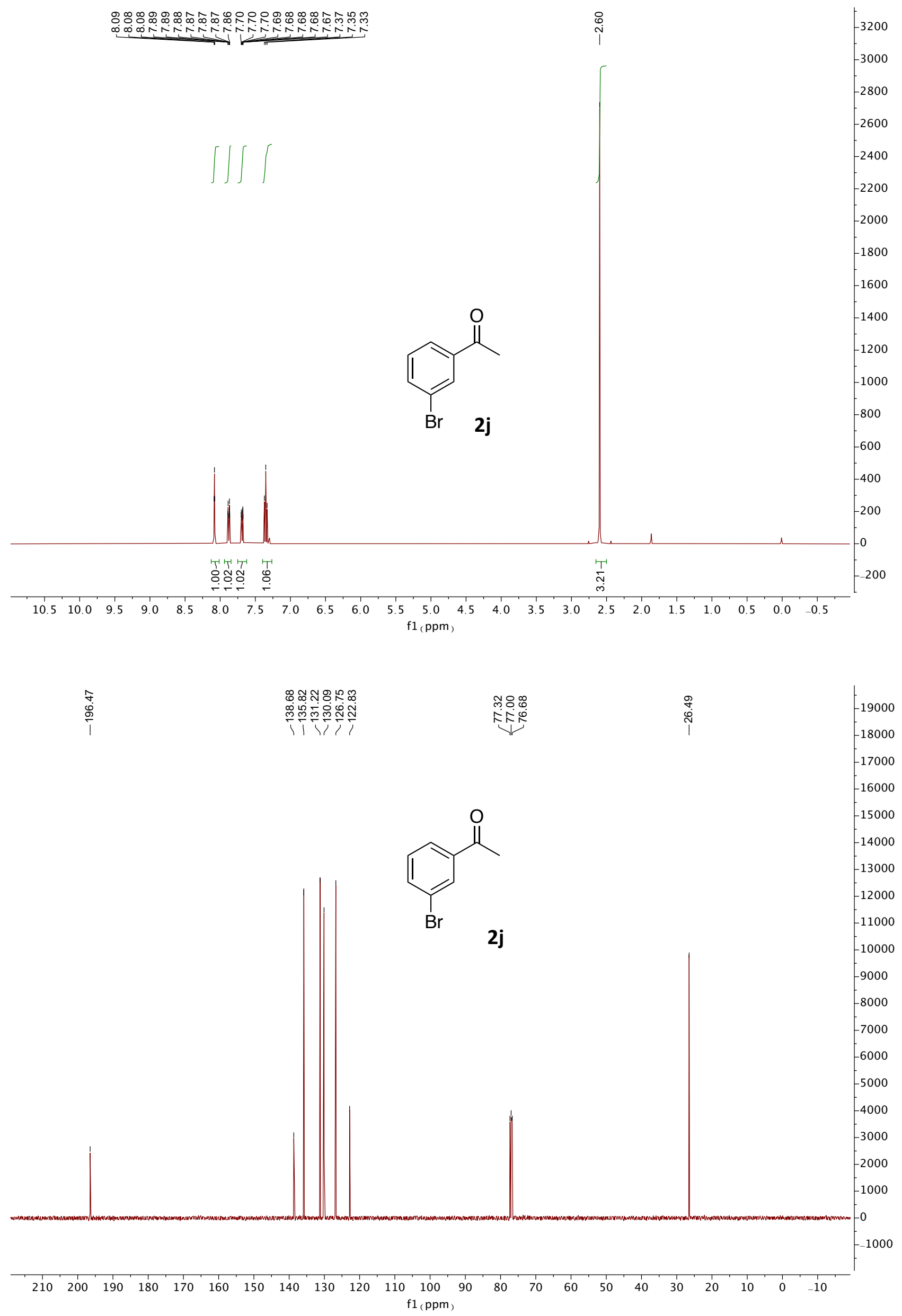




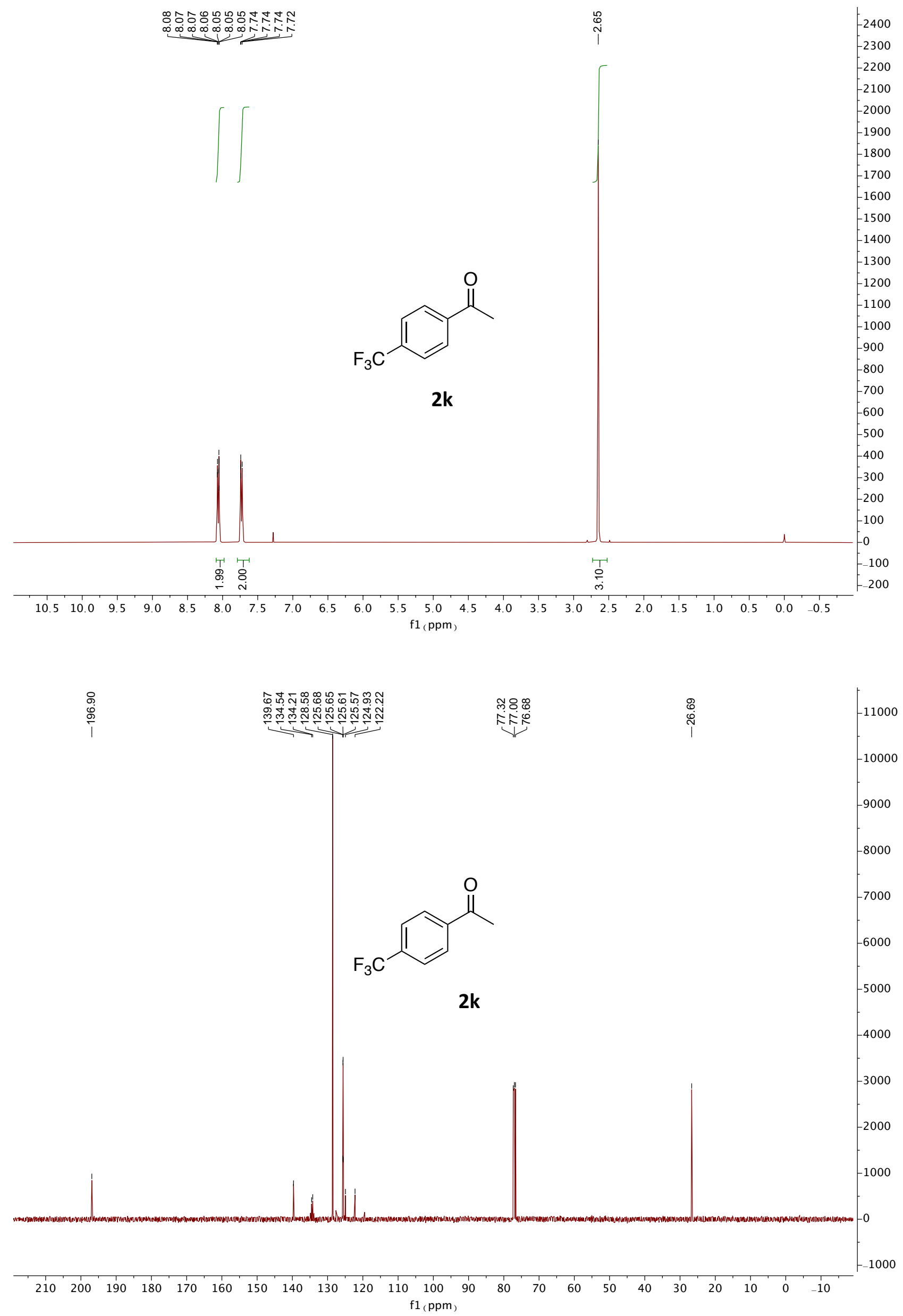



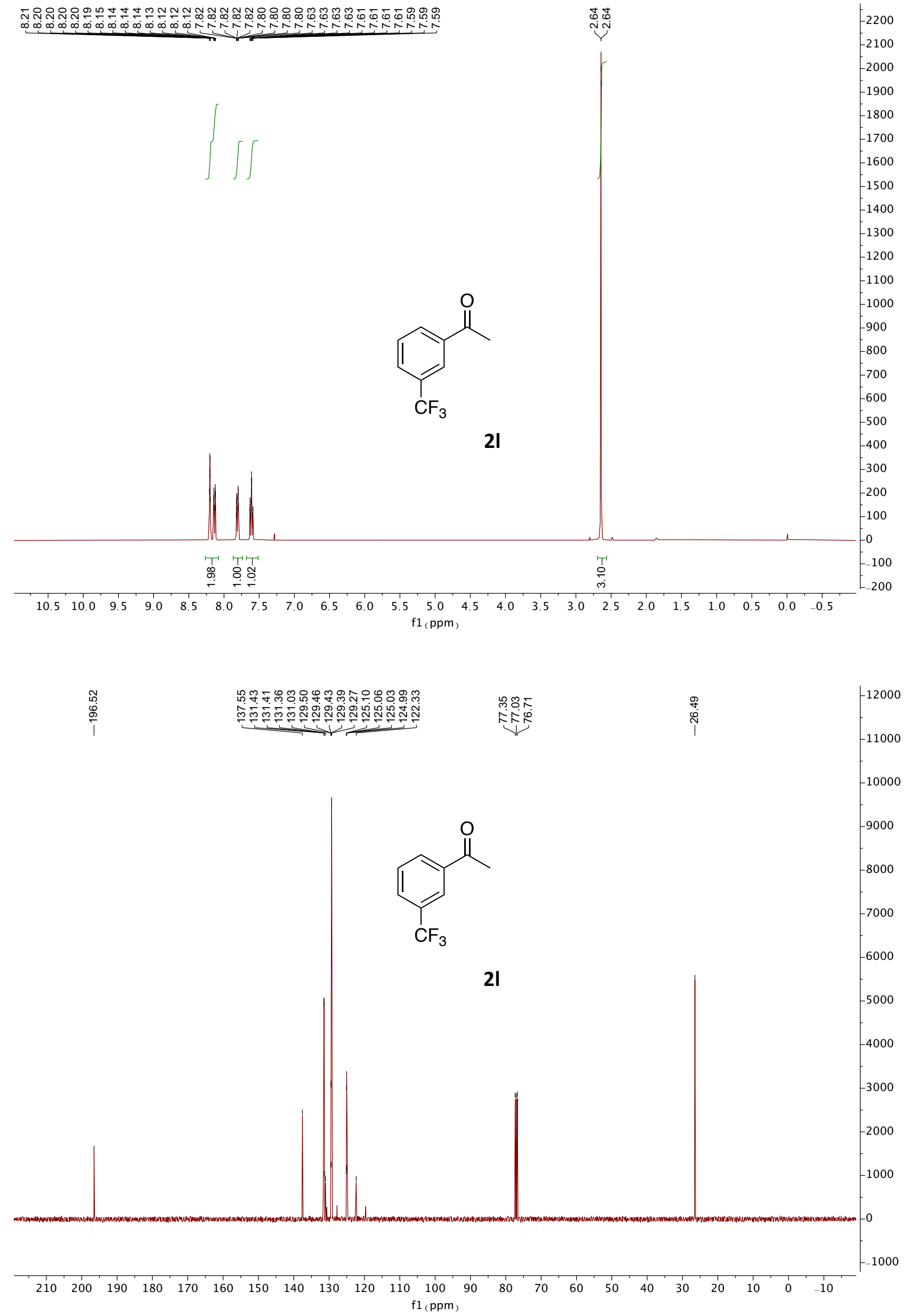


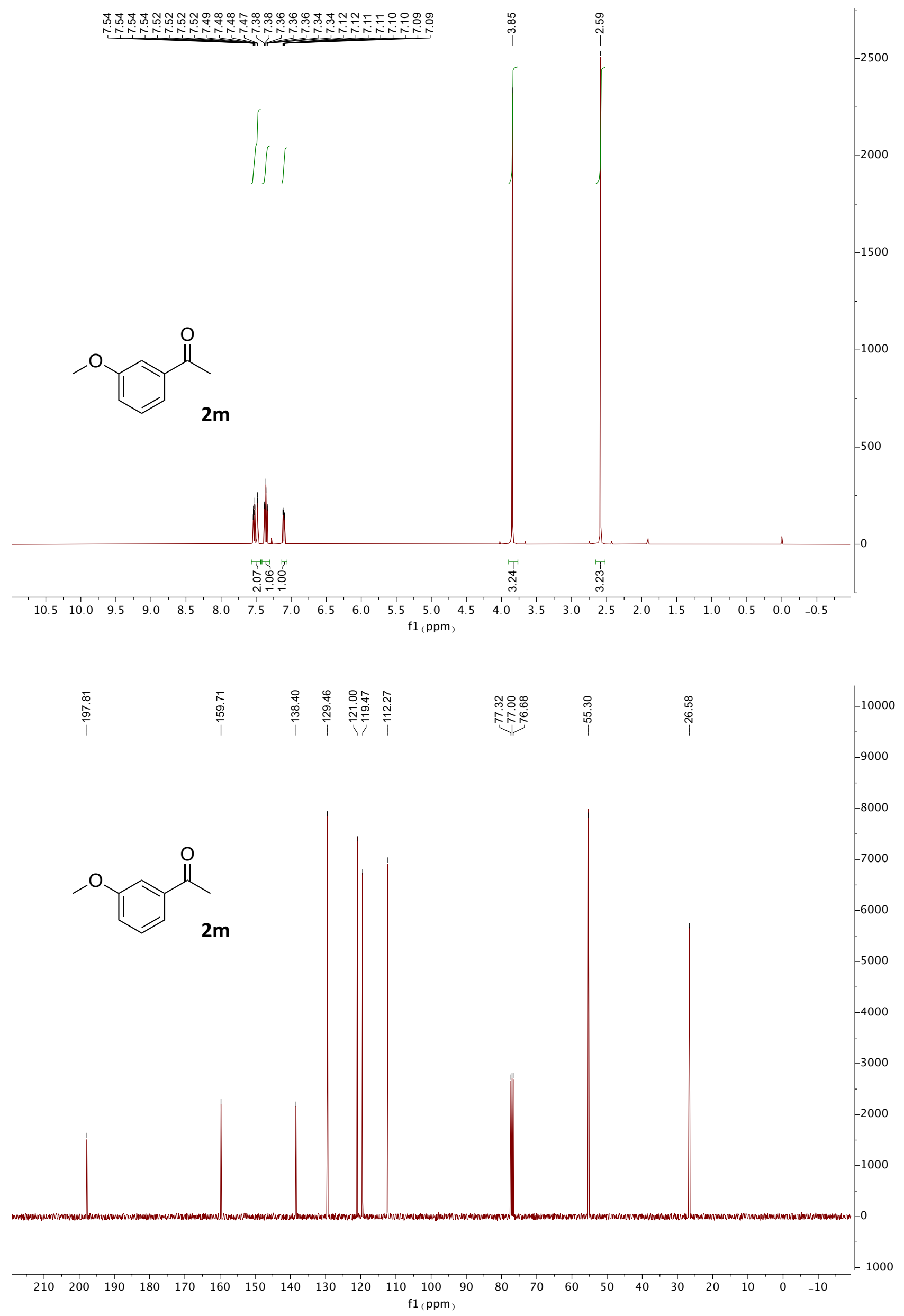



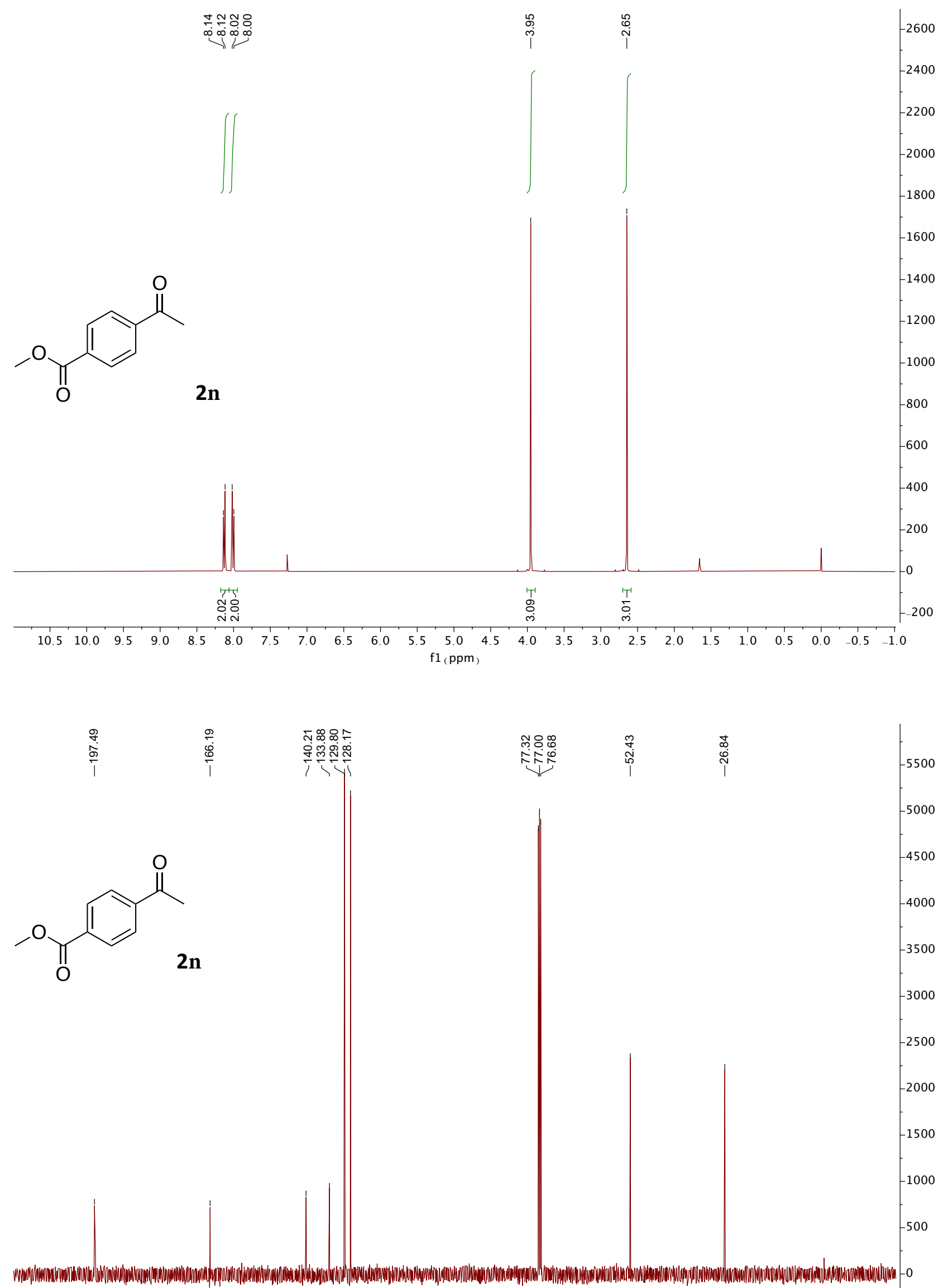

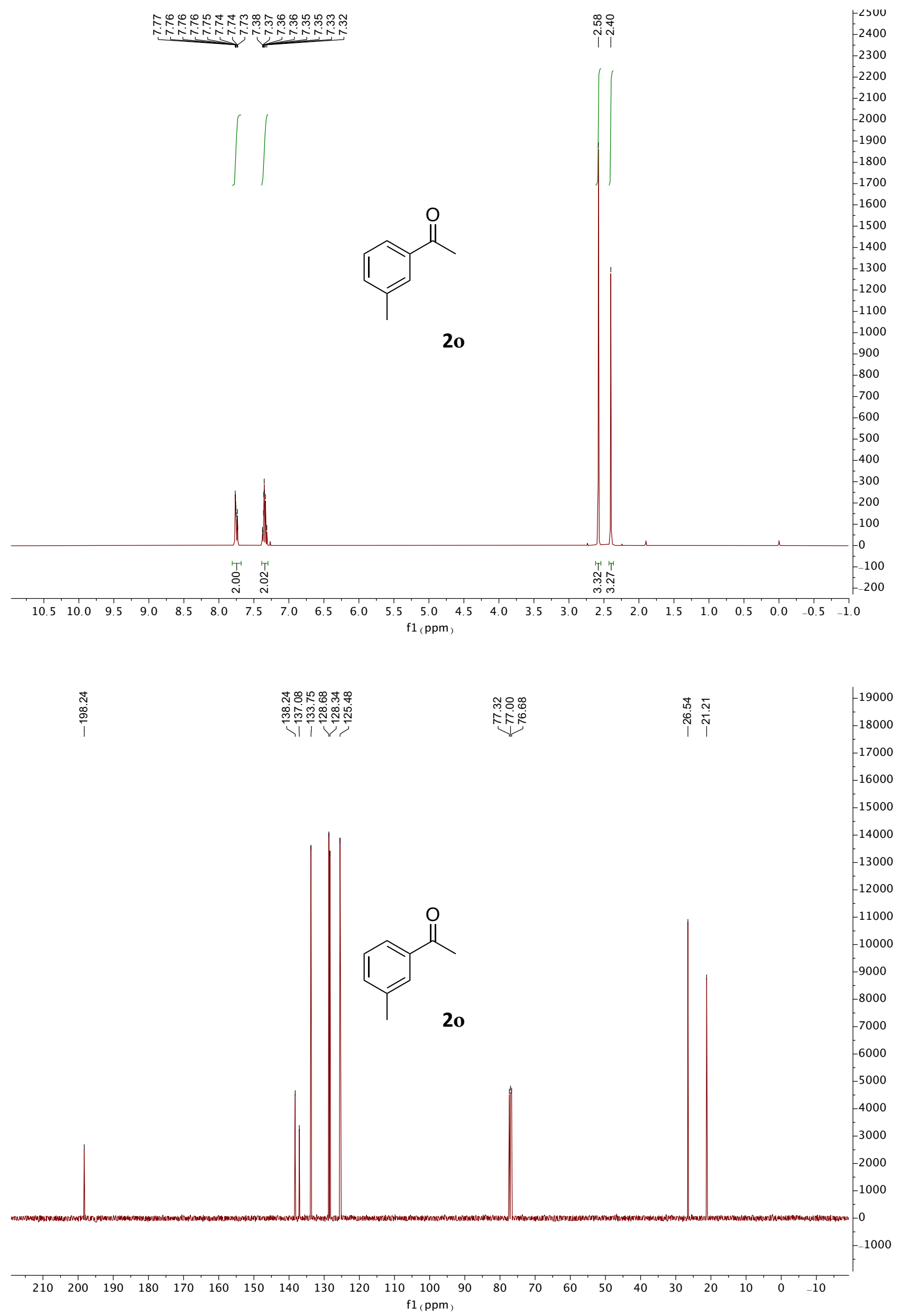


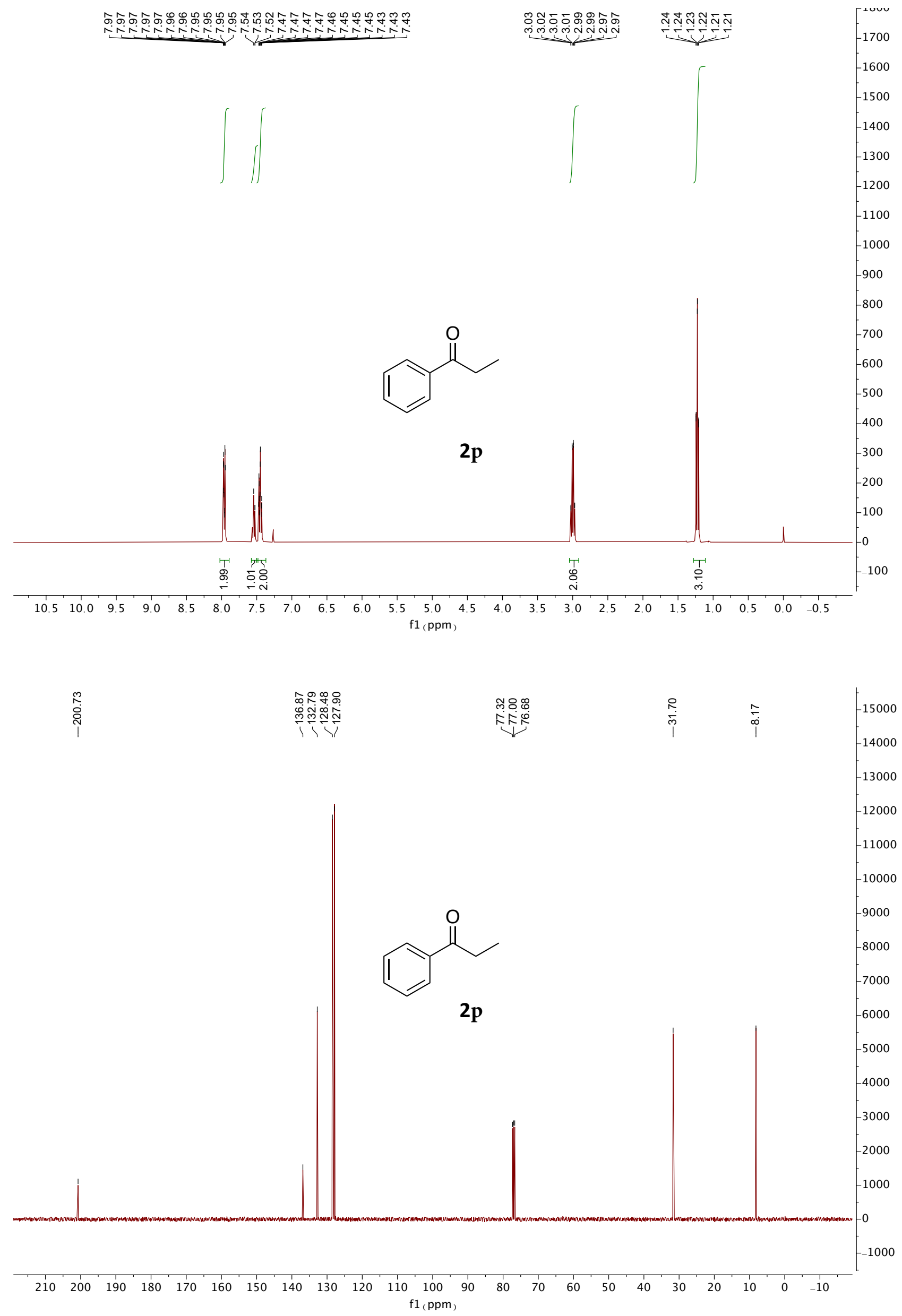



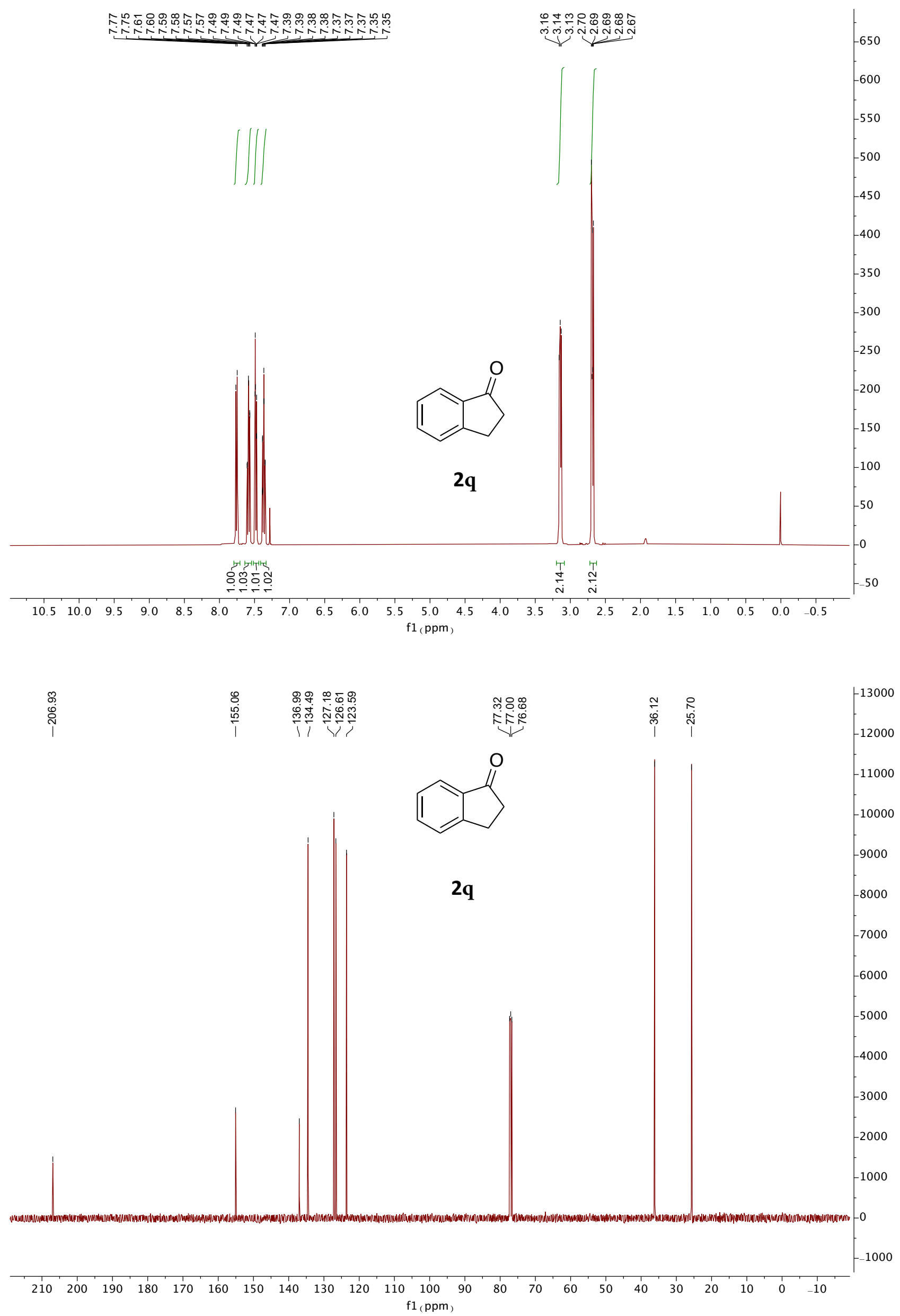

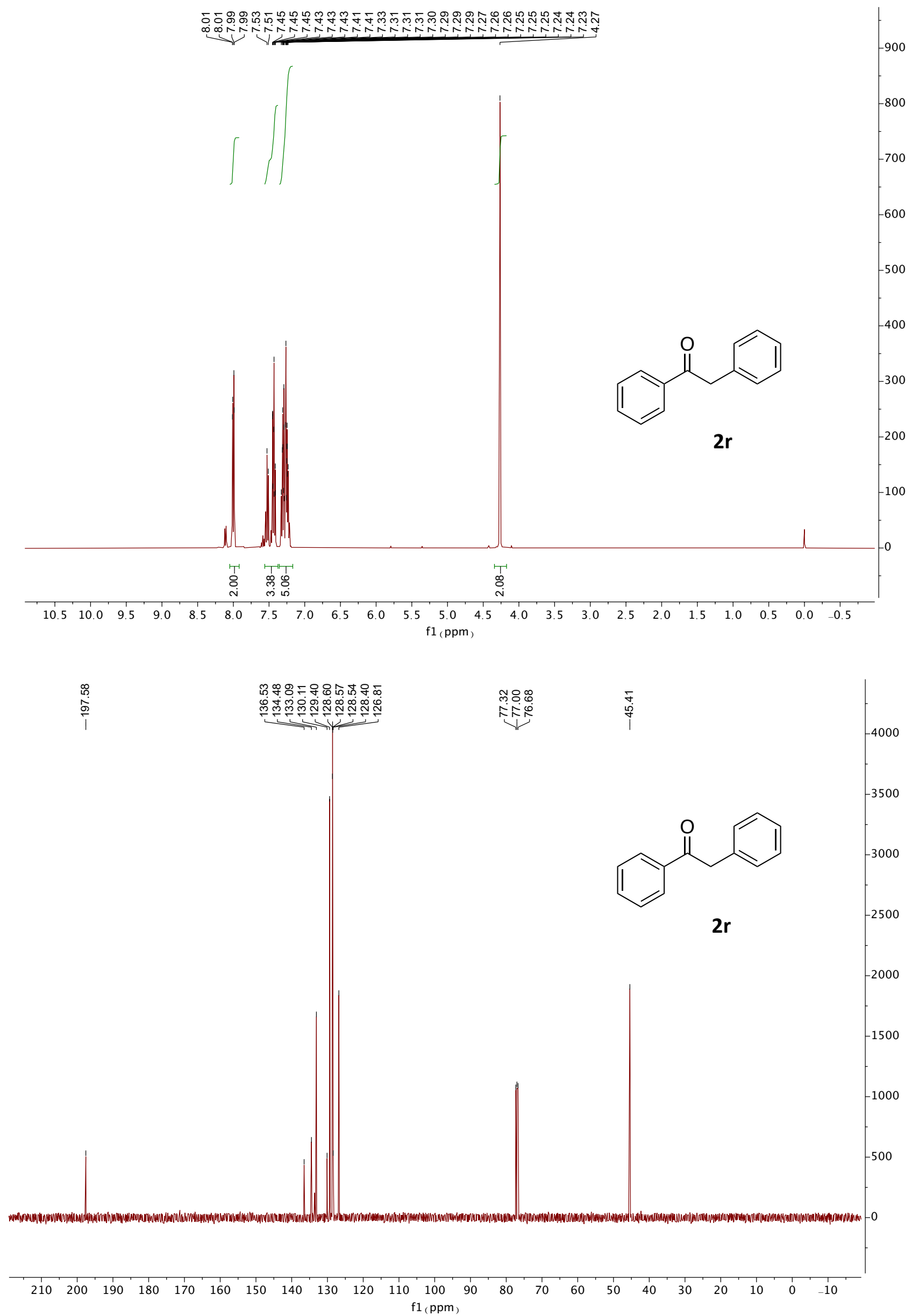


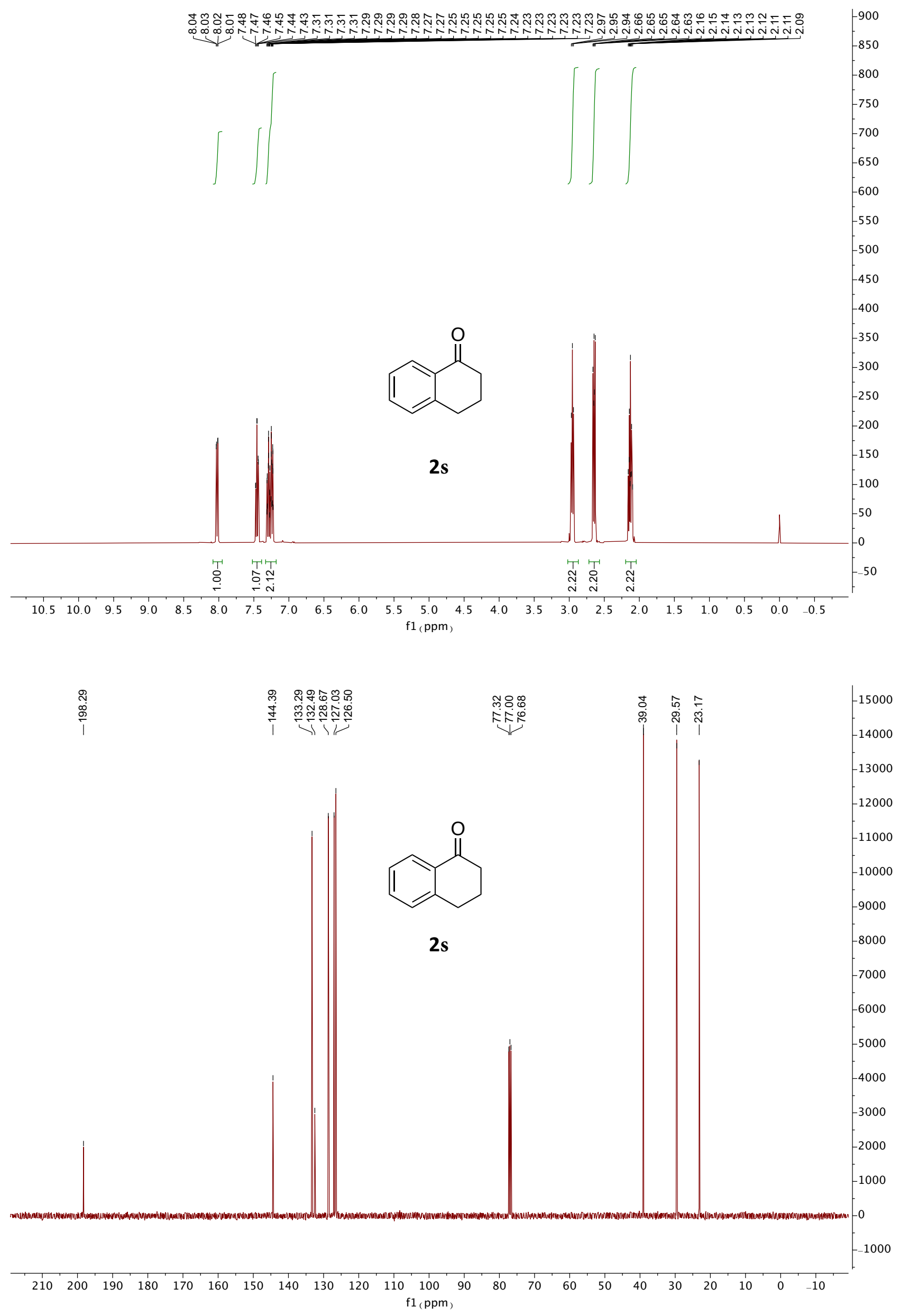



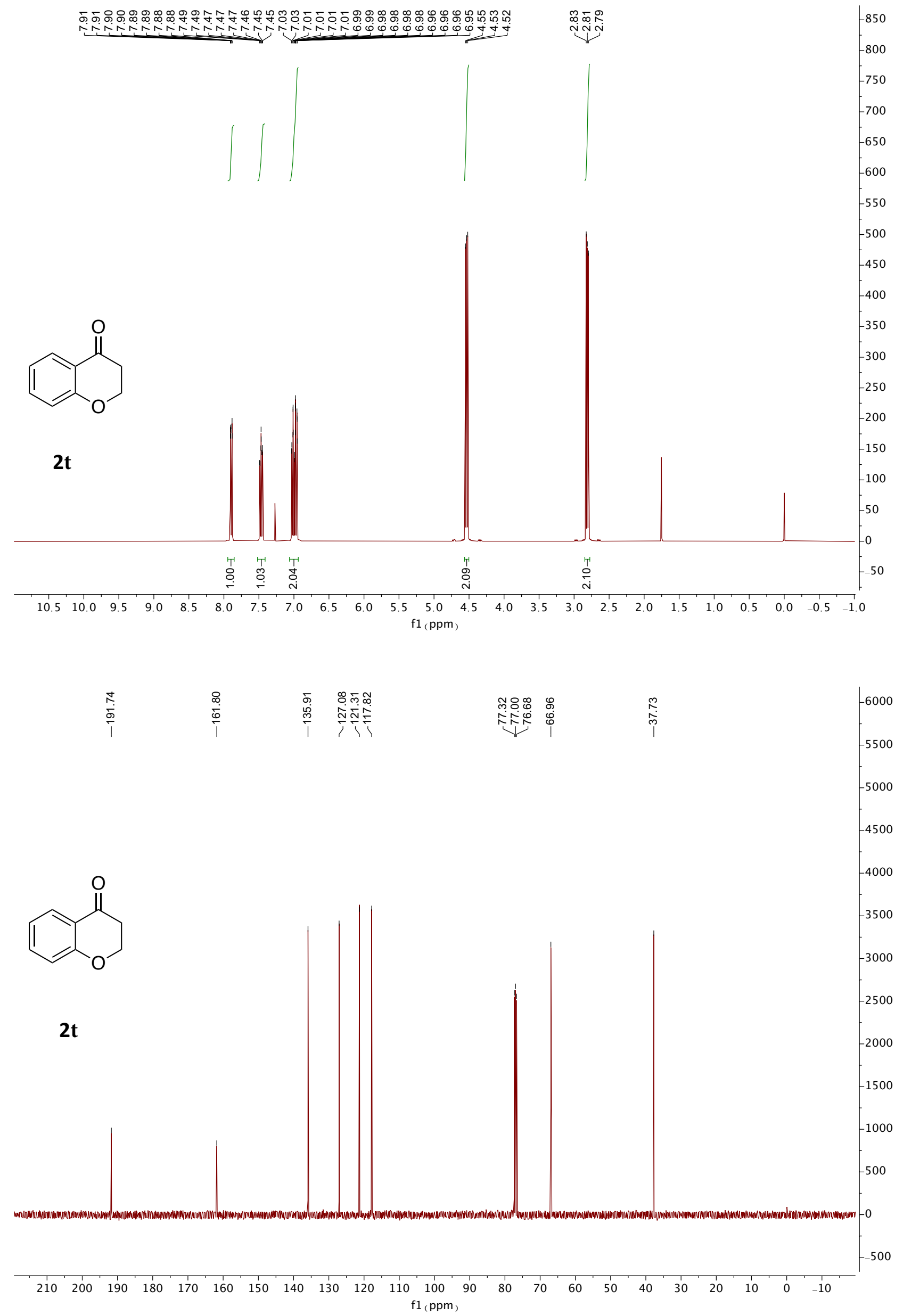